
WSRC-TR-92-370

\section{HYDRAULIC TESTING OF TYPE Q SEPTIFOILS INCLUDING MODIFICATIONS (U)}

by J. L. Steimke

Westinghouse Savannah River Company

Savannah River Site

Aiken, South Carolina 29808

Other Authors:

M. D. Fowley

H. N. Guerrero

This paper was prepared in connection with work done under Contract No. DE-AC09-89SR18035 with the U. S. Department of Energy. By acceptance of this paper, the publisher and/or recipient acknowledges the U.S. Government's right to retain a nonexclusive, royalty-free license in and to any copyright covering this paper, along with the right to reproduce and to authorize others to reproduce all or part of the copyrighted paper. 
NRTSC

NUCLEAR REACTOR TECHNOLOGY

DE93 004547 AND SCIENTIFIC COMPUTATIONS KEYWORDS:

Septifoil

Type Q

Control rod

RETENTION:

PERMANENT

\section{Hydraulic Testing of Type Q Septifoils Including Modifications (U)}

by

John L. Steimke, Mark D. Fowley and Hector N. Guerrero

ISSUED: September 1992

METRR 
DOCUMENT:

TITLE:

REVISION NUMBER:

TASK:

TASK NO.:
WSRC-TR-92-370

Hydraulic Testing of Type $Q$ Septifoils

Including Modifications (U)

0

Septifoil Leakage and Verification

92-057-1

APPROVALS

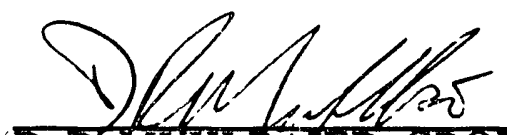

D.R. MUHLAIER, GROUPMANAGER

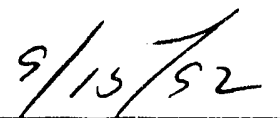

DATE

Algano-t

$9 / 15 / 92$

A.J.GARRETT, NES MANAGER

DATE

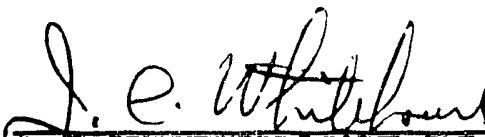

J.C.WHITEHOUSE, TECHNICAL REVIEWER

$9 / 15 / 92$

$\frac{\text { Oshu dteinke, }}{\text { J. CSTETMKE, AUTHOR }} 9 / 15 / 92$

Mont D

$\frac{9 / 15 / 93}{\text { DATE }}$

M. D. FOWLEY, AUंTHOR

A.N Iremens

$9 / 15 / 92$

H. A. GUERERO, AUTHOR 


\section{Table of Contents}

Introduction 1

Summary 1

Apparatus 2

Non-Prototypicalities 3

Instrumentation and Data Acquisition 4

Experimental Procedure 5

QA Considerations $\quad 6$

Test Matrices and Results for Original Control Rod Hardware 6

Test Matrices and Results for Modified Control Rod Hardware 8

$\begin{array}{ll}\text { Conclusions } & 9\end{array}$

$\begin{array}{ll}\text { References } & 10\end{array}$

Tables 11

$\begin{array}{ll}\text { Figures } & 20\end{array}$

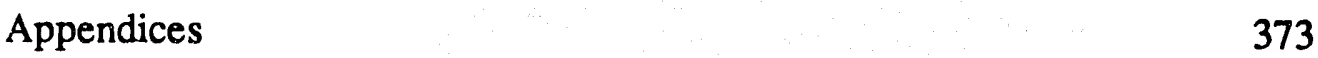


WSRC-TR-92-370

\section{Hydraulic Testing of Type Q Septifoils Including Modifications (U)}

\section{Introduction}

On May 25, 1992 a leak of moderator was detected as K Reactor was approaching initial criticality. The partial length control rods were being withdrawn when the leak detectors in the Process Room alarmed. The apparent location of the moderator leak was the top of the guide tubes which are positioned over the new Type $Q$ septifoils. The reactor was shut down immediately. A good summary of the leak is given by Punch [1992]. In response, a testing program was begun at the Heat Transfer Laboratory (HTL). The goals of the program were to determine the cause of the septifoil leak and to test methods for preventing future leaks.

\section{Summary}

A Type $Q$ septifoil, seven control rods and a guide tube assembly were installed in the Long Term Flow Facility (LTFF) of the HTL. The first series of tests determined that the sources of the leak at K Reactor were the long, hollow extension tubes over the partial length control rods. Water flows into the extension tube through the bottom holes which, depending on the elevation of the partial rod, can be located in a relatively high pressure location in the septifoil. The water flows out the top hole of the extension tube and some of it flows out the top of the guide tube assembly. Leaks had not been observed for the previous Type J septifoil because internal pressures were lower for the Type J than for the Type Q.

Tests in the HTL were run in support of four proposed methods to solve the problem. The first method was to reduce blanket gas pressure from $5 \mathrm{psig}$ to $3.5 \mathrm{psig}$. This reduced internal pressures in the septifoil. The second method was to reduce the septifoil cooling water flow from about $106 \mathrm{gpm}$ to $70 \mathrm{gpm}$. This also reduced internal pressures in the septifoil. The third method was to modify the extension tube over each partial control rod by drilling extra holes through it along its length. The purpose of the extra holes was to allow the water flowing inside the extension tube to leak out inside the septifoil before it reached the guide tubes. Scoping tests [Fowley, 1992] showed that this method was only marginally successful and no critical data were taken. The fourth method was to modify the partial length rods to make them hydraulically almost identical to full length rods [Banks, 1992]. The full length rods have a shorter extension tube than the partial length rods and the bottom hole on the extension tube is: high enough in the septifoil that it can not be positioned in a high pressure region of the septifoil. All methods except for drilling extra holes effectively solve the leakage problem. The methorl of reducing septifoil cooling flows was used for a month at K Reactor. Currently, the method of modifying the partial length rods to make them hydraulically similar to the full length rods is the preferred long term solution.

Most of the HTL tests were run with the control rods held stationary at prescribed elevations corresponding to the range of control rod positions expected during reactor operation. Some tests were run with the control rods moving with the same speeds and in the same order as for reactor operation including scram. The water level inside the guide tubes over the septifoil was measured by the use of sight tubes connected to pressure taps on the guide tubes or by pressure gages. Freeboard, the distance from the water level in a guide tube to the top of the guide tube assembly, provides a measure of the margin of safety. Pressures were measured at tank bottom and inside the septifoil. The target tank bottom pressure for the experiments was $12.76 \mathrm{psig}$ which gives the same no-flow freeboard as a blanket gas pressure of 5.00 psig in K Reactor. The 
minimum freeboard measured for the reduced flow method for a flow of 70 gpm and adjusted to the target tank bottom pressure was 11 inches. The smallest freeboards were measured for positions of controls rods that would be seen during a reactor scram. Freeboards for normal reactor conditions were larger. The minimum freeboard measured for partial length control rods modified to be nearly identical hydraulically to full length rods was 35 inches for a flow of 106 gpm and 25 inches for $120 \mathrm{gpm}$, both were adjusted to the target tank bottom pressure. The hardware change has been shown to be very effective. It allows the previous septifoil flowrate to be restored and yields higher freeboards than the method of reducing flowrate.

Two of the 61 Type Q septifoils in K Reactor contain a neutron source rod in their central position. The source rod is largely hollow and it hydra:lically resembles the current design of partial control rod. Present practice is to remove the source rods from the reactor during power ascension. However, removing them when the septifoil flow is $106 \mathrm{gpm}$ would likely result in an overflow. The source rods must be addressed but are beyond the scope of this report. In the near future, experiments will be conducted to test a design change for the source rod which would prevent overflow.

\section{Apparatus}

The new Type Q septifoil was hydraulically tested in the HTL. The reason for replacing the former Type $J$ with the Type $Q$ was to assure cooling of the control rods during a hypothetical LOCA [Steimke, 1991]. The Type Q septifoil would remain full of water even if the reactor tank drained. Figure 1 shows a side view of the Type Q septifoil in K Reactor. Coolant enters from the bottom, flows past the seven control rods and out the slots and holes near the Poison Plate. The elevations of the control rods are used to control reactor power and axial flux shape. Fifty nine of the sixty one septifoils in K Reactor contain two partial length lithium control rods, three full length lithium control rods and two full length cadmium control rods. In the other two septifoils one of the cadmium control rods, the one in the central position, is replaced with a neutron source rod. The control rods and the source rod are illustrated in Figures 2, 3 and 4 . The full length lithium control rods have lithium-aluminum alloy, the active material, extending the full length of the core. Above the active region is a hollow extension tube with holes at either end. The holes allow some circulation of coolant and also allow coolant to drain when the rod is removed from the reactor. The present partial length rods have a shorter active region and a long hollow region above the active region in the extension tube. The modified partial length rods have the same size active region as the present partial rods, but have solid aluminum above the active material. The hollow extension tubes for the full length lithium control rods and the modified partial length control rods are the same length and are nearly identical. The only difference is two extra holes drilled through the modified extension to facilitate identification. Above each cadmium rod is a solid extension tube. The source rod is largely hollow and has perforations. The source is positioned near the mid plane of the core when the source ror is fully down. All of the extension tubes have a knob at the top which can be gripped to lift the rod.

Tests were conducted at the LTFF of the HTL. The LTFF has a tank and a hydraulic loop. It does not have a hydraulic plenum, shield or Poison Plate but its total height is the same as $\mathrm{K}$ Reactor. The distance from tank bottom to tank top is 239.5 inches. The LTFF is shown in Figure 5. A reactor grade septifoil was placed in the central position of the tank. A pressure tap was added 0.85 inch above the top of the oval slots where the coolant discharges. Since the LTFF does not contain a top shield or a Poisnn Plate and these structures are located close to the discharge holes of the septifoil, a simulated top sinield and a simulated Poison Plate were added. The simulated plates were one inch thick Lexan (8) disks separated by 0.75 inches. The bottom of the top plate was flush with the bottom of the semi-permanent sleeve. Both plates have an outside diameter of 7.63 inches. The inside diameters of the shield simulator and the Poison Plate simulator are 4.25 and 4.75 inches, respectively. 
Seven reactor grade control rods were placed inside the septifoil. For the initial scoping tests and the first series of critical data tests, two were partial length and five were full length. All seven were the lithium type of control rod. In the reactor two of the five full length control rods in a septifoil are the cadmium type. The external appearance and hydraulics of the cadmium type are slightly different than for lithium full length rods, as shown in Figures 2 and 3. They were not available for use in the first series of critical data tests. The present arrangement of the control rods in the septifoil is shown in Figure 6. The control rods are designated by both number and letter. The perforated web inside the septifoil is not shown. Note that the partial rods are opposite each other and that central position is occupied by a cadmium control rod. All critical data tests involving the modified partial rods were done with two cadmium full length rods, three full length lithium rods and two modified partial length control rods.

A reactor grade guide tube assembly was placed over the septifoil as shown on Figure 1. The guide tube assembly consists of seven tubes clustered in a hex. The six outside tubes were labeled $\mathrm{A}$ through $\mathrm{F}$ as indicated in Figure 6. Pressure taps were attached to the outside tubes 102.9 inches below the top of the guide tube assembly. Note that there was no pressure tap on center tube because no technique was found to accomplish this without blocking one of the other six tubes. A scoping run was performed in which the equivalent blanket gas pressure was raised to the point of spill over to determine when the central tube of the guide tube assembly would leak in relation to the other cadmium rod position. The test showed that the water level in the central position was within one inch of the water level in the other cadmium position.

\section{Non-prototypicalities}

The following are the non-prototypicalities of the test and the justifications for why they do not affect applicability of the data to the reactor.

I. The tests were run with ordinary water rather than with heavy water.

Justification: Code Development Group members have analyzed the differences in freeboard between heavy and light water for the experiment [Shadday, et al., 1992]. They used the fact that the tank pressure in the experiments was adjusted so that the no-flow freeboard in the experiments was the same as the no-flow freeboard in the reactor with 5 psig blanket gas pressure. They concluded that liquid density has no effect. Liquid viscosity was also shown to have a negligible effect.

II. The experiment simulated the pressure in the tank by the use of a water column above the tank rather than blanket gas.

Justification: The method of creating the pressure boundary condition makes no difference to the results of the experiment.

III. The experiment simulated the Poison Plate and the shield in the reactor with plastic disks.

Justification: The only effect of those two plates on septifoil flow is that they could increase the hydraulic resistance just outside the exit holes of the septifoil. The disks correctly simulated that resistance. It should be noted that the addition of the two plates in scoping tests had a negligible effect on freeboard.

IV. The pin that provided flow to the septifoil in the experiment has less hydraulic resistance than the pins at K Reactor.

Justification: The experiments were controlled on the basis of flow to the septifoil rather than pressure at the inlet pin. Therefore, the difference in resistance did not effect the 
experimental results.

V. The seven control rods in the guide tube assembly hang from latches. The two latches for the partial length control rods were prototypical. However, the other five latches were not.

Justification: The problem being addressed was caused by flow through the hollow extensions over the partial control rods. The flow was driven by the lower hole in the partial rods being exposed to a pressure gradient larger than the hydrostatic pressure gradient. The holes in the extension over the full length rods are exposed only to the hydrostatic pressure gradient. Therefore, there will be no flow out of the upper hole of the full length control rod extension. A non-prototypical latch would make a difference only if there was flow in that region.

VI. The upflow pin in the bottom of the reactor tank fits inside a hole in the bottom of the septifoil. There is a slip fit but no seal. The design specifications of the two components imply a diametral clearance of from 6 mils to 11 mils. The diametral clearance for the experiment is 5 mils.

Justification: The only significance of the clearance is that water can leak through the gap when there is a pressure difference between the inside and outside of the septifoil. Calculations for the leak flow indicate that it will be negligible for all clearances up to 11 mils for the pressure differences expected under normal operation.

YII. In most cases the water level inside the guide tubes is measured with sight tubes attached to the guide tubes. Sight tubes are not present at the reactor.

Justification: Under steady operating conditions the sight tubes have no hydraulic effect. Under transient conditions, the sight tubes increase the effective volume of the guide tubes and therefore damp fluctuations. During the transient experiments where damping would distort the result, the sight tubes were replaced by pressure transducers.

VIII. In some tests in the HTL there was no flow in the Mark 22 assemblies surrounding the septifoil. In K Reactor those assemblies would carry a flow.

Justification: There is no hydraulic connection between the flows in the Mark 22 asce mblies and the septifoils.

\section{Instrumentation and Data Acquisition}

Flow to the sepifoil was measured using a orifice plate meter (TR-20267) connected to a differential pressure gage (TR-20267-1). The pressure gage has a current output which was converted to a voltage using a calibrated resistor TR-1387. The overall uncertainty on flow is \pm 2 gpm. All uncertainties are based on $95 \%$ confidence level. Tank bottom pressure was measured using Heise pressure gage TR-428 at the same elevation as the tank bottom. The uncertainty is \pm 0.05 psi. A pressure tap was installed in the side of the septifoil just above the outlet slots, 184.9 inches above tank bottom. Prior to July 20 the pressure at that tap was measured with a Sensotec absolute pressure gage (TR-20075) located 225.2 inches above tank bottom. Its uncertainty is \pm 0.25 psi. After July 20 the pressure at that tap was measured with a Heise pressure gage at the same location, TR-436. Its accuracy is $\pm 0.08 \mathrm{psi}$. The pressures at the gages were referenced to the elevation of the tap. The supply pressure to the septifoil pin was measured using a Heise pressure gage (TR-432) located 11.5 inches below tank bottom. The location of the pressure tap is shown on Figure 3. The uncertainty is \pm 0.25 psi. Barometric pressure was measured with TR-710. The uncertainty is \pm 0.09 inch $\mathrm{Hg}$. The temperature of the 
water in the tank was measured with a Type $\mathrm{J}$ thermocouple. The uncertainty is $\pm 2.2^{\circ} \mathrm{C}$.

For most of the tests transparent $1 / 2$ " outside diameter Tygon (2) tubes were connected to the pressure taps on the guide tube assembly. The sight tubes lead upward and were strapped to the guide tube assembly to allow visual measurement of the water level in each guide tube. The tubes extended six feet higher than the guide tube assembly. However, this additional length was not necessary because water flowed out of the top of the guide tubes when the level in the sight tubes was higher than the top of the guide tube assembly. Freeboard was measured with a ruler and manually recorded in the laboratory notebook (WSRC-NB-91-158). Freeboard is the distance from the top of the guide tube assembly to the water level in a sight tube. Freeboards were usually reported to the nearest inch. For the last tests involving moving control rods the sight tubes were removed and the pressures inside two guide tubes were measured using Heise pressure gages, TR-434 and TR-300. The sight tubes had the advantage that no calibration was required and freeboard could be measured directly. Also, instrument drift was not an issue. The sight tubes had the disadvantages that the water volume in the tube damped the transient response and that no continuous data record could be made. Therefore, Heise pressure gages were used for transient experiments. The calibration of Heise pressure gages was spot checked every day to detect drift. No significant drift was detected. The uncertainty for these two gages is \pm 1 inch of water.

The flow, temperature and pressures were recorded with a Macintosh computer based data acquisition system using Workbench $\otimes$ software. M. D. Fowley prepared a Workbench worksheet which tells the computer which data channels to sample, the sampling rate, how large the signal will be and the equations for converting the voltage signals to engineering units. Workbench stores the voltage and engineering unit data for each run in tabular form using a file name supplied by Fowley, who also recorded the conditions of the test and the file name in the logbook. Data were reduced using Trapeze $\otimes$ software. Data files generated by Workbench were imported into the Trapeze spreadsheet prepared by J. L. Steimke which computed time averages of the measured variables and made plots of some of the variables versus time. The computed averages for each run were electronically copied into the data tables in this report.

\section{Experimental Procedure}

This is a summary of the written procedure for this test [Hovis, 1992]. The actual procedure deviated from the written procedure in one respect. The written procedure calls for process water to flow through the assembly once and then dump to the drain. The actual method was to circulate the water with the LTFF pump. The tank drain valves were closed and the tank vent valve was opened to allow the tank to be filled. When the tank level reached a foot or less from the top the vent valve was closed. Filling was continued at a low flow until water, but no admixed air, flowed out of the overflow bucket. The pump in the LTFF loop was started and the desired flow was set. The makeup water flow was adjusted so that a small flow of water continuously flowed out of the over flow bucket. The position of the overflow bucket could be adjusted; however for almost all experiments described here the overflow bucket created a tank bottom pressure of about 12.7 psig.

For the tests with stationary rods the instruments were watched until steady state was achieved. Then data were logged and the freeboards in the guide tubes were observed and recorded. For the tests with moving control rods, data was logged while the rods were moving.

For some tests prior to July 29 one or two of the six measured freeboards were anomalous. Investigation revealed the cause. The control rods all have slight bows over their lengths. Therefore, it is possible for a control rod to press against the inside of a pressure tap hole. When this happened the measured freeboard would change slowly or not at all. The results for runs 
containing anomalous data are not reported here. The solution this problem was to rotate each control rod before recording data.

\section{QA Considerations}

All requirements for critical data in 1Q34 were met. The experiments were performed following an approved Critical Task Plan [Zagrodnik, 1992] and Technical Procedure [Hovis, 1992]. All of the instruments had current calibrations before the start of testing and were given post-test calibrations. This report was technically reviewed.

QAP IV-1 of 1 Q34 requires that data acquisition software be verified by the user. Workbench and Trapeze were simultaneously verified by means of a loop calibration. There are three types of instrumentation; pressure gages, a thermometer and a flow meter. The loop calibration for the pressure gages consisted of pressurizing the flow loop under a no flow condition with two different heads of liquid measured with a ruler. The Workbench worksheet was used to log the outputs both times. The Trapeze spreadsheet was used to time average the data. The output pressures agreed with the known hydrostatic heads. The thermocouple in the flow loop was checked by removing it from the loop while keeping it connected to the DAS. It was placed in stirred beakers of water at two different temperatures with a calibrated glass thermometer. The output of the Trapeze spreadsheet agreed with the thermometer reading. A loop calibration of the flow meter was performed at the same time as the post-test calibration for the flow meter. The voltage output of the flowmeter was connected to both a voltmeter and the DAS. For every flow of the calibration data were logged on the DAS. The Trapeze spreadsheet was used to time average the results. The Trapeze flows agreed with the calibration flows. Details of the loop calibration are reported in Appendix A.

\section{Test Matrices and Results for Original Control Rod Hardware}

Tests to address the proposal to reduce blanket gas pressure were run in a scoping mode. They showed that reducing the blanket gas pressure increased freeboards by an amount equal to the head equivalent of that pressure change. Reducing blanket gas pressure was never the preferred solution and no qualified data were taken to support that solution. A summary of the early scoping tests appears in Appendix B.

The test matrix for the stationary rod tests to address the solution of decreasing septifoil flow is shown in Table 1. The rod elevations are the heights of the rod bottoms with respect to the orifice plate near the bottom of the septifoil. Several septifoil flows were used. The average normal flow to septifoils in the reactor is $106 \mathrm{gpm}$. The original proposed throttled flow was 68 gpm. This was later adjusted upward to $70 \mathrm{gpm}$. The other flows were run to test for sensitivity.

One series of tests was done with the original hardware, a flow of $70 \mathrm{gpm}$ and an equivalent blanket gas pressure of 5 psig in which the rods were moved in the order and with the speeds that they would be moved during startup and scram. Therefore, possible rod movements in the reactor were duplicated during testing. The purpose was to observe whether the stationary tests missed any important phenomena. Initially ail seven control rods in the reactor are fully down. During reactor startup the two partial control rods are lifted about 36 inches and held there. The $\mathrm{G}$ cadmium rod is pulled out of the reactor, followed by the $E$ cadmium rod and the $\mathrm{B}, \mathrm{C}$ and $\mathrm{F}$ lithium control rods. A full length control rod is pulled completely out of the reactor core before the next is moved. Therefore, during normal operation only one full length rod is at an intermediate position. The other full rods are either fully up or fully down. The reactor will become critical during some movement of the $C$ rod or the $F$ rod. The maximum speed at which rods can be withdrawn is 16 inches per minute. During a reactor scram all full rods are driven into the reactor at a speed of 1.6 inches per second. The procedure for these transient tests is listed in Appendix C. The results of the transient tests are listed in Appendix D. Whitehouse 
[1992] explains the rationale for the experiments with moving control rods. There were no unexpected observations during the experiments with moving rods. Freeboards were consistent with those measured with stationary control rods.

Results for the test matrix in Table 1 are shown in Table 2 . Some runs are duplicated. The day and time are listed to allow access to the data files on the DAS computer. The tank pressure measurement is located at tank bottom. The supply pressure, $\mathrm{P}_{\text {pin }}$, is located $11.5^{\prime \prime}$ below tank bottom. The septifoil pressure is located just above the oval exit holes. The freeboards for the six guide tubes are with respect to the top of the guide tubes. The temperature listed is for the water. The reactor blanket gas pressure forces moderator up the guide tubes to an elevation of 10 ' 3" under no flow conditions. The top of the guide tube assembly is at an elevation of 16' 4". Therefore, the freeboard for no flow through the septifoil is 73 " for both the reactor and the laboratory tests.

Figure 7 illustrates one of the trends wherein freeboard decreases with increasing septifoil flow, while holding rod position constant. Extrapolating the data suggests that the freeboard would become zero for a flow of roughly $85 \mathrm{gpm}$ when the partial rods are at 18 " and the full rods are at 0 ". The flow to K Reactor septifoils last May was about $106 \mathrm{gpm}$. Therefore, the laboratory result is consistent with the fact that a spill occurred when the full rods were at 0 " and the partial rods were at the somewhat higher elevation of 36 inches. The reason that freeboard decreases with increasing flow is that pressure losses inside the septifoil are proportional to the square of flowrate. The data in Figure 7 were replotted in Figure 8 in a way that creates a linear plot. The difference between the freeboard under flowing conditions and the freeboard with no flow is related to the hydraulic losses through the septifoil. Hydraulic losses are expected to be proportional to flow squared. Therefore a plot of the difference between the no flow freeboard and the flowing freeboard vs. flow squared should be a linear plot going through the origin. This plot, Figure $\delta$, is nearly linear and extrapolates to the origin.

Figure 9 illustrates a trend observed at startup. The freeboard for the partial rods decreases when the partial rods are lifted from the full down position when the other rods are kept down and flow is held constant. For a flow of $68 \mathrm{gpm}$ the partial rod freeboard decreases by 30 inches when the partial rods are lifted 12 inches. Then the freeboard is fairly constant over a range of partial rod heights. The decrease in freeboard would be greater for larger flows. This explains why no spilling was observed in $\mathrm{K}$ Reactor until the partial rods were lifted. The reason for the decrease in freeboard is that the top holes on the partial rod extension enter the bottom of the guide tubes when the partial rods are elevated six inches. At this elevation the bottom holes on the extension are in a frictional pressure gradient below the septifoil exit holes and are exposed to a pressure higher than hydrostatic. That pressure drives water into the hollow extension. The flow exits the extension inside the guide tube and increases the pressure there. That increased pressure raises the liquid level and decreases the freeboard. When the partial rods are fully down the top holes on the extension are below the guide tubes in a relatively open region and the freeboard is not decreased. This mechanism decreases the freeboard for the partial rods only. Freeboards are greater for the full length rods.

Figures 10 and 11 are from experiments, differing slightly in flow, which show a trend that is observed during a scram. There is a relative minimum in freeboard when the full length rods are 100 inches higher than the partial rods. The reason is that particular height difference aligns the bottom tips of the full length rods with the bottom holes on the partial rod extensions.

Therefore, the flow area decreases in the vicinity of the rod tips which generates a pressure drop. The outlet pressure for the septifoil is fixed. Adding a pressure drop upstream for a fixed flow increases the pressure upstrearn. The increased local pressure at the lower holes on the partial rod extension drives more flow into them and up the extension. 


\section{Test Matrices and Results for Modified Partial Control Rods}

A series of tests were run to test the proposed solution of modifying the partial control rods to make them hydraulically nearly identical to the full control rods as shown in Figures 2 and 3. The only difference was two additional $3 / 8$ " holes drilled midway between the top and bottom holes of the extension tube. The test matrix for the stationary rod tests [Guerrero, $1992 j$ to address this modification is shown in Table 3. The partial rods were moved to 36 inches and three intermediate positions with all the full rods in. Then tests were performed with the full rods successively pulled out. Each test run with a different control rod position was conducted at the nominal flow of $106 \mathrm{gpm}$ and repeated at $120 \mathrm{gpm}$ to simulate the maximum flow variation. The equivalent blanket gas pressure was 5 psig. The results are listed in Table 4 and summary plots of the minimum freeboard are given in Figlires 12 and 13. Zero Veeder Units means that all five full rods are fully out and $5000 \mathrm{VU}$ means all five full rods are fully in. The minimum freeboard was measured at a value of 41 inches for the case when the flow was $106 \mathrm{gpm}$, the partial length rods are at 36 inches, and all the full length rods are out. This minimum freebcard decreased to 32 inches when the flow was increased to $120 \mathrm{gpm}$.

Two series of tests were run with modified rods to examine the situation during startup when the partial rods are lifted together, but the full length rods with the exception of the $G$ rod are fully down. This senes of tests was similar to the series plotted in Figure 9, except that in the earlier series the $G$ rod was down and the partial rods had not been modified. The first series, shown in Figure 14, with modified partial rods was done lifting rods $A$ and $D$ together, the two partial rods. The second series, shown in Figure 15 , was a variation in which rods $C$ and $F$ were lifted together. This would not ordinarily be done in the reactor. One reason for running the second series was to determine if the extra identification holes in rods $A$ and $D$ made a hydraulic difference. For both series of tests the freeboard for all rod positions is equal when the rods are all fully down. As the pair of rods is raised the freeboard decreases for all rod positions, but more for the pair being raised. The minimum freeboard occurs when the pair of rods is raised about 10 inches. The minimum freeboard for a flow of $120 \mathrm{gpm}$ was 34 inches. Increasing the flow from $106 \mathrm{gpm}$ to $120 \mathrm{gpm}$ decreases the freeboard by at most twelve inches. The extra identification holes in rods $A$ and $D$ cause a difference in the freeboard of about three inches.

The freeboard in the central guide tube was not instrumented. Therefore, there was concern that the freeboard might be different than for the other cadmium position. A scoping test was run in which the equivalent blanket gas pressure was increased until the freeboards were high enough so they could we observed visually from the top of the guide tube assembly. The difference in freeboards for the two cadmium rods was less than one inch, which is considered negligible.

Transient tests were run with modified partial control rods using the procedure outlined in Appendix C. A limitation of the experiment should be noted. The hoist used to lift and lower the control rods had 130 inches of travel, so that the rods could not be moved the full 177 inches in one smooth motion. When a rod was lifted, the crane was used to lift it from zero elevation to 130 inches. The rod was then moved manually to 177 inches. This resulted in a gap in the data and sometimes resulted in a discontinuity in the data plots. Freeboards, pin pressures and flow were logged once per second. Plots of freeboards and pin pressure are shown in Figures 16 through 21 . Because the raw data were noisy, a running average over five seconds was computed and plotted. The plots show periods when the rods are stationary as well as periods when the rods are moving. Vertical lines indicate the boundaries between clata sets. Sometimes hours passed in that interval. Freeboards are plotted for tubes $\mathrm{A}$ and $\mathrm{C}$ of the guide tube assembly that were instrumented with pressure gages. Tube A contains a partial rod and tube C contains a full length rod. Sight tubes were attached to the other tubes. Visual observations were made of the sight tubes. The visual observations in the sight tubes were consistent with the measurements made with the pressure gages. The position of the rods was not instrumented. 
Therefore, the septifoil pin pressure is plotted as an indication of rod position. The pin supplies flow to the septifoil. The pin pressure remains constant, although somewhat noisy, as long as the rods are motioniess. When the rods are lifted the hydraulic resistance of the septifoil decreases and the pin pressure decreases and vice versa. The pin pressure was used to determine when the rods started their motion and when they stopped.

Measured freeboards during the transients covered a range of 47 to 59 inches of freeboard for a flow of $106 \mathrm{gpm}$. Transient tests were not run for a septifoil flow of $120 \mathrm{gpm}$. However, for the steady stare tests the largest difference in freeboards observed for flows of 106 and 120 grm was 12 inches. Subtracting 12 inches from 47 inches gives 35 incines, which is greater than the guideline freeboard of 24 inches. Tabular results from this test are listed in Table 5.

Freeboards listed are arithmetic averages for a run including those runs which are transients. As with the previous transient iest there were no unexpected observations during the experiments with moving rods and freeboards were approximately the same as those measured with stationary control rods. There were some dynamic effects. The largest dynamic effect in the plots was when five control rods were scrammed in Figure 20. Only after rod motion is complete does the freeboard for rube $\mathrm{C}$ decrease by about six inches to its equilibrium value of 52 .

There were some discontinuities in the plots as the result of the previously mentioned discontinuity in rod movement. In Figure 17, at 400 seconds the first full length rod has been lifted from zero to 130 inches. At 520 seconds the first rod is at 177 inches and the pressure is inwer by an amount expected for the additional rod uavel. The freeboard plot, Figure 16, also

$\omega$ 's a discontinuity of four inches at 1100 seconds resulting from the rod 2 being lifted the i. 47 inches. The discontinuities are small compared with the difference between the micasured freeboards and the criterion freeboard of 24 inches.

\section{Conclusions}

Tests in the Heat Transfer Laboratory identified the cause of the septifoil overflow at $\mathrm{K}$ Reactor on May 25, 1992. Moderator flowed up through the long hollow extension rod on the partial length control rod and out the top of the guide tube assembly. The understanding of the mechanism acquired as the the result of the initial tests was used to identify possible solutions to the problem. Modifying the partial length control rods to make them hydraulically nearly identical to the full length control rods allows a return to the full septifoil flow of $106 \mathrm{gpm}$ and increases the freeboard as compared to the original hardware and a flow of $70 \mathrm{gpm}$. 


\section{References}

Banks, J, J., 1992, “Design Input for PMT-92-0797"

Flach, G. P., 1992, “Source Rod Test Matrix Request”, NES-CDG-920143, August 6.

Fowley, M. D., 1991, “Type Q Septifoil Hydraulic Test”, WSRC-TR-91-125.

Fowley, M. D., 1992, laboratory notebook, WSRC-NB-91-158, pp. 197-205.

Guerrero, H. N., 1992, “ Additional Septifoil Tests,” NES-E1H-920261, July 30.

Hovis, G. L., 1992, “Septifoil Leakage Tests”, TP-92-024, May 29. Punch, T. M., 1992, “Septifoil Guide Tube Overflow During K14.1 Startup”, WSK, IR-92-42-
064.

Shadday, M. A.., 1991, "Hydraulic Characteristics of the Type Q Septifoil”, WSRC-TR-
91-612.

Shadday, M. A., N. M. Askew, G. P. Flach and L. D. Koffman, 1992, "Type Q Septifoil Guide Tube Freeboard; Model Description and Results (U), WSRC-TR-92-357.

Steimke, J. L., 1991, “Design and Testing of Septifoil Modification", Rev. 2, Task Plan 90074-1, May.

Steimke, J. L., Hovis, G. L., Hart, C. M., Fowley, M. D., Whitehouse, J. C., 1992 "Measurements of Septifoil Freeboard", NES-ETH-92014, June 3.

Steimke, J. L., 1992, "Septifoil Leakage Test Matrix,"NES-ETH-920255", July 28.

Whitehouse, J. C., 1992, "Test Matrix for Control Rod Startup and Scram Tests", NES-ETH920201, June 4.

Zagrodnik, A. A., 1992, "Septifoil Leakage Verification and Resclution", Technical and QA Plan, Task 92-057-1, Rev. 3. 
Table 1

Septifoil Leakage Test Matrix

- Original Part Length Control Rods

For all tests the tank bottom pressure is $12.76 \pm 0.10$ psig which corresponds to a blanket gas pressure of 5 psig. After runs 5 through 11 were completed they were repeated in the same order to allow an estimate of variability. Elevation is above orifice plate.

\begin{tabular}{|c|c|c|c|c|c|c|c|}
\hline run & $\begin{array}{l}\text { flow } \\
\text { gpm }\end{array}$ & $\begin{array}{l}\text { part rods } \\
\text { elev. } \\
\text { inch }\end{array}$ & $\begin{array}{l}\text { rod G } \\
\text { elev. } \\
\text { inch }\end{array}$ & $\begin{array}{l}\operatorname{rod} 2(\mathrm{E}) \\
\text { elev. } \\
\text { inch }\end{array}$ & $\begin{array}{l}\text { rod } 3(B) \\
\text { elev. } \\
\text { inch }\end{array}$ & $\begin{array}{l}\text { rod } 4(C) \\
\text { elev. } \\
\text { inch }\end{array}$ & $\begin{array}{l}\operatorname{rod} 5(F) \\
\text { elev. } \\
\text { inch }\end{array}$ \\
\hline 1 & 68 & 18 & 72 & 72 & 72 & 72 & 0 \\
\hline 2 & 68 & 18 & 159 & 159 & 159 & 159 & 0 \\
\hline $\begin{array}{l}3 \\
4\end{array}$ & 68 & 24 & 123 & 123 & 123 & 123 & 0 \\
\hline $\begin{array}{l}4 \\
5\end{array}$ & 68 & 18 & 12 & 12 & 12 & 12 & 12 \\
\hline $\begin{array}{l}5 \\
6\end{array}$ & 68 & 18 & 0 & 0 & 0 & 0 & 0 \\
\hline 6 & 58 & 18 & 0 & 0 & 0 & 0 & 0 \\
\hline 7 & 78 & 18 & 0 & 0 & 0 & 0 & 0 \\
\hline 8 & 68 & 15 & 0 & 0 & 0 & 0 & 0 \\
\hline 9 & 68 & 12 & 0 & 0 & 0 & 0 & 0 \\
\hline 10 & 68 & 21 & 0 & 0 & 0 & 0 & 0 \\
\hline 11 & 68 & 24 & 0 & 0 & 0 & 0 & 0 \\
\hline 12 & 68 & 18 & 123 & 123 & 123 & 123 & 0 \\
\hline 13 & 68 & 24 & 130 & 130 & 130 & 130 & 0 \\
\hline 14 & 68 & 24 & 140 & 140 & 140 & 140 & 0 \\
\hline 15 & 68 & 24 & 150 & 150 & 150 & 150 & 0 \\
\hline 16 & 68 & 18 & 177 & 159 & 159 & 159 & 0 \\
\hline 17 & 68 & 18 & 159 & 159 & 159 & 177 & 0 \\
\hline 18 & 68 & 18 & 117 & 117 & 117 & 117 & 0 \\
\hline 19 & 68 & 18 & 177 & 159 & 177 & 177 & 0 \\
\hline 20 & 73 & 18 & 177 & 159 & 177 & 177 & 0 \\
\hline 21 & 68 & 0 & 0 & 0 & 0 & 0 & 0 \\
\hline 22 & 73 & 0 & 0 & 0 & 0 & 0 & 0 \\
\hline 23 & 70 & 18 & 159 & 159 & 159 & 159 & 0 \\
\hline 24 & 70 & 18 & 164 & 164 & 164 & 164 & 0 \\
\hline 25 & 70 & 18 & 154 & 154 & 154 & 154 & 0 \\
\hline 26 & 70 & 12 & 113 & 113 & 113 & 113 & 0 \\
\hline 27 & 68 & 8 & 109 & 109 & 109 & 109 & 0 \\
\hline 28 & 106 & 0 & 0 & 0 & 0 & 0 & 0 \\
\hline 29 & 70 & 0 & 0 & 0 & 0 & 0 & 0 \\
\hline 30 & 70 & 18 & 0 & 0 & 0 & 0 & 0 \\
\hline 31 & 70 & 8 & 109 & 109 & 109 & 109 & 0 \\
\hline 32 & 68 & 19 & 114 & 114 & 114 & 114 & 0 \\
\hline 101 & 70 & 21 & 0 & 0 & 0 & 0 & 0 \\
\hline 102 & 70 & 21 & 12 & 12 & 12 & 12 & 0 \\
\hline 103 & 70 & 21 & 72 & 72 & 72 & 72 & 0 \\
\hline 104 & 70 & 21 & 119 & 119 & 119 & 119 & 0 \\
\hline 105 & 70 & 21 & 118 & 118 & 118 & 118 & 0 \\
\hline 106 & 70 & 21 & 120 & 120 & 120 & 120 & 0 \\
\hline 107 & 70 & 21 & 122 & 122 & 122 & 122 & 0 \\
\hline
\end{tabular}


Table 1 (Continued)

Septifoil Leakage Test Matrix

- Original Part Length Control Rods

\begin{tabular}{llllllll} 
run & $\begin{array}{l}\text { flow } \\
\text { gpm }\end{array}$ & $\begin{array}{l}\text { part rods } \\
\text { elev. }\end{array}$ & $\begin{array}{l}\text { rod G } \\
\text { elev. } \\
\text { inch }\end{array}$ & $\begin{array}{l}\text { rod 2 (E) } \\
\text { elev. } \\
\text { inch }\end{array}$ & $\begin{array}{l}\text { rod 3 (B) } \\
\text { elev. } \\
\text { inch }\end{array}$ & $\begin{array}{l}\text { rod 4 (C) } \\
\text { elev. } \\
\text { inch }\end{array}$ & $\begin{array}{l}\text { rod 5 (F) } \\
\text { elev. } \\
\text { inch }\end{array}$ \\
\cline { 5 - 7 } 108 & 70 & 21 & 121 & 121 & 121 & 121 & 0 \\
109 & 70 & 21 & 159 & 159 & 159 & 159 & 0 \\
110 & 75 & 21 & 120 & 120 & 120 & 120 & 0 \\
111 & 70 & $21,26^{*}$ & 120 & 120 & 120 & 120 & 0 \\
112 & 70 & $21,16^{*}$ & 120 & 120 & 120 & 120 & 0 \\
113 & 70 & 21 & 110 & 110 & 110 & 110 & 0 \\
114 & 70 & 21 & 115 & 115 & 115 & 115 & 0 \\
115 & 70 & 21 & 125 & 125 & 125 & 125 & 0 \\
116 & 70 & 21 & 130 & 130 & 130 & 130 & 0 \\
117 & 70 & 21 & 105 & 105 & 105 & 105 & 0 \\
118 & 70 & 21 & 135 & 135 & 135 & 135 & 0 \\
119 & 70 & 21 & 120 & 120 & 120 & 120 & 0
\end{tabular}

* Note the positions of the two partial rods differ by 5 inches. 
4 昰实

is

츨

N

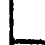

$\circ$

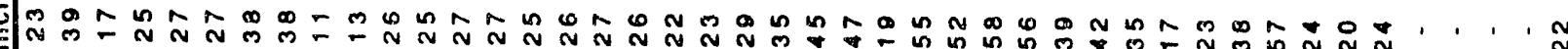

(1)

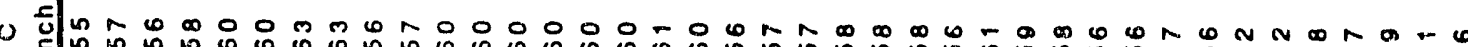
$\exists$

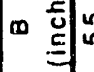

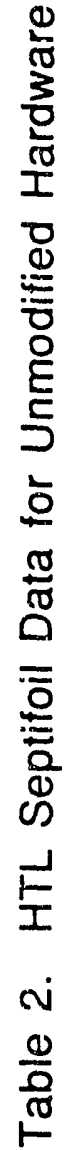

$<$ 司象

$\infty \infty$

$m \infty$

$\infty \log \theta$

n 0

00

0000

$\therefore-\circ \infty$

舟

<

$\stackrel{\text { N }}{\text { N }}$

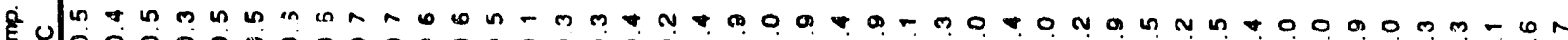

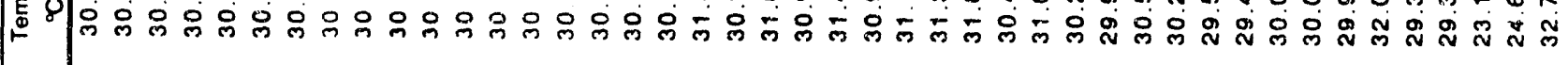

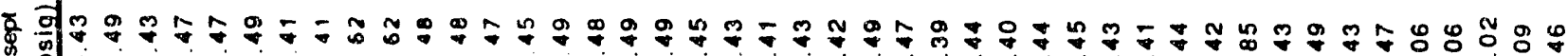

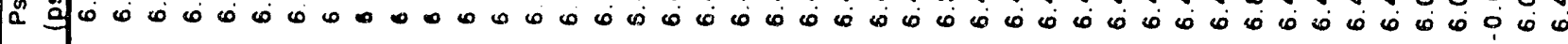

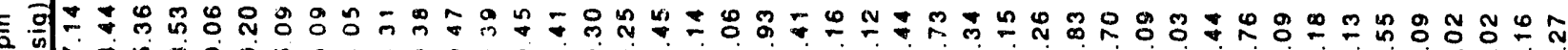
a 霖

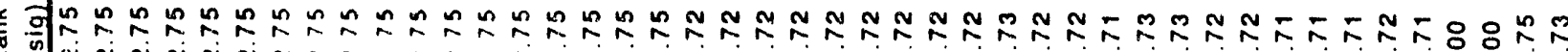

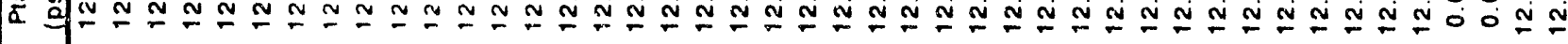

3 हौ

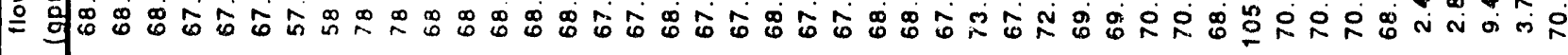

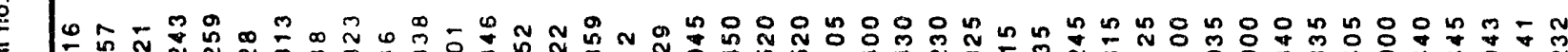
言

둔 운 E

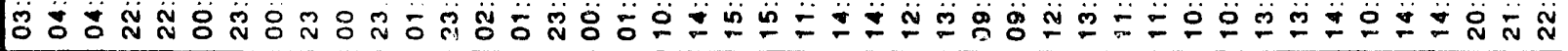

W

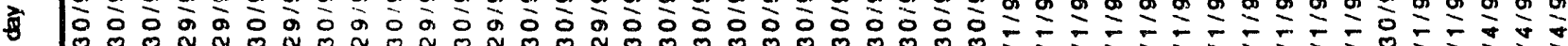

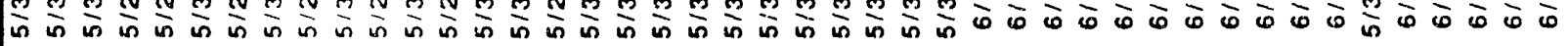

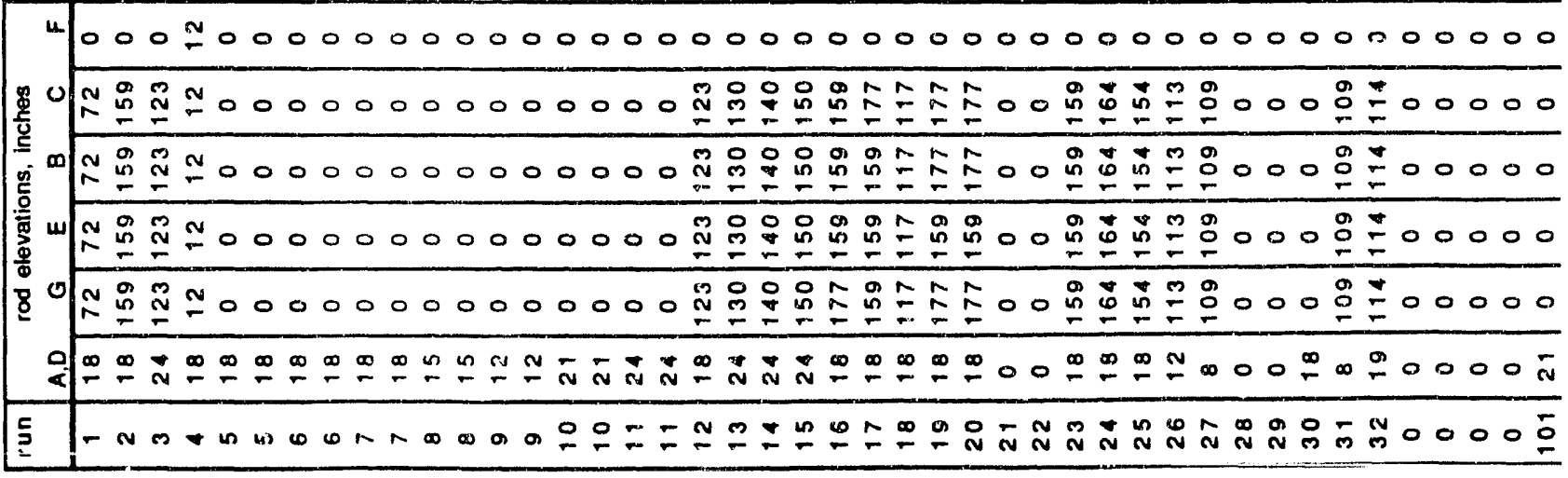




\begin{tabular}{|c|c|}
\hline 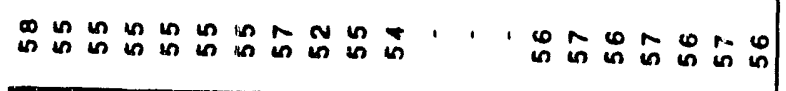 & \multirow{6}{*}{ 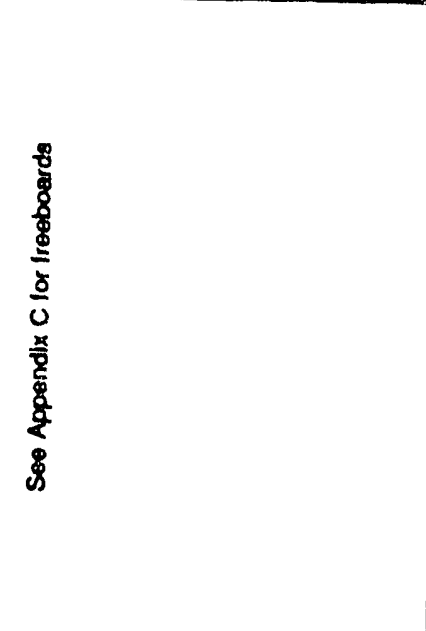 } \\
\hline 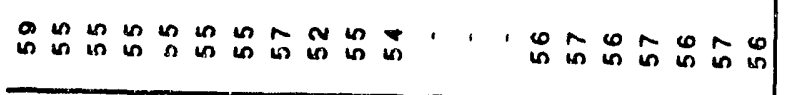 & \\
\hline - & \\
\hline 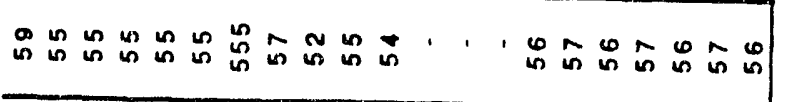 & \\
\hline 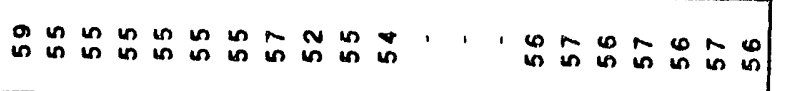 & \\
\hline 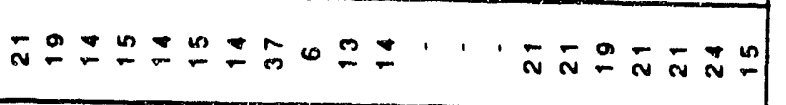 & \\
\hline 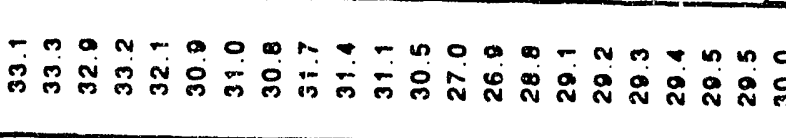 & 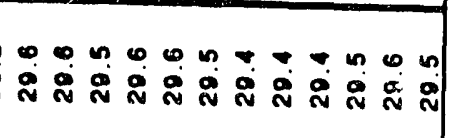 \\
\hline 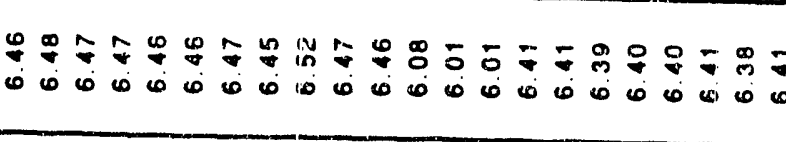 & 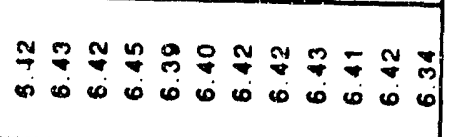 \\
\hline
\end{tabular}

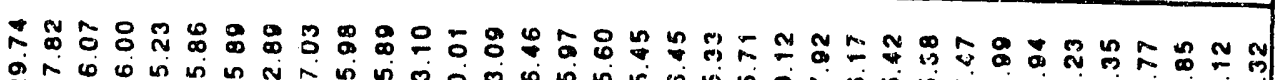

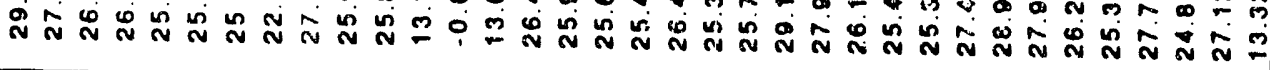

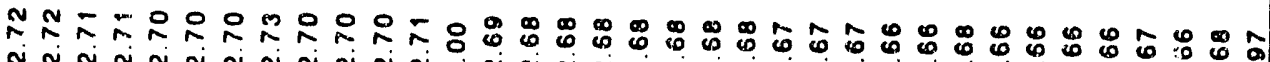

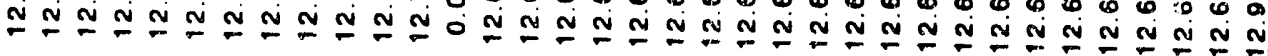

זง

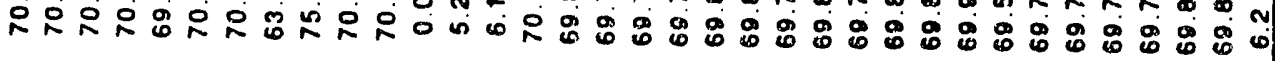

蜍

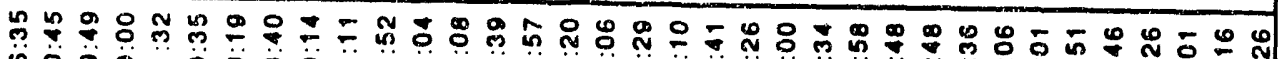

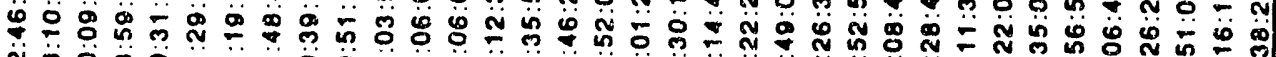

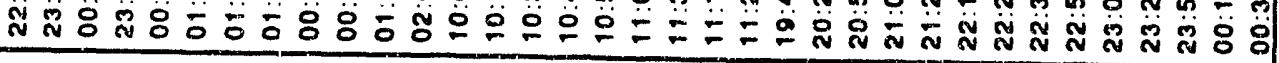

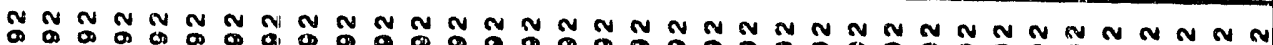
a

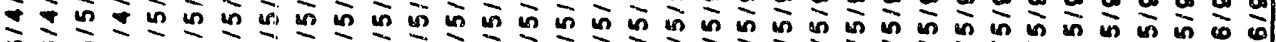

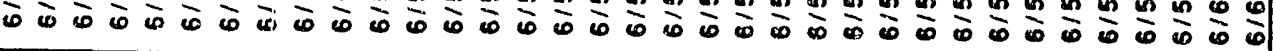

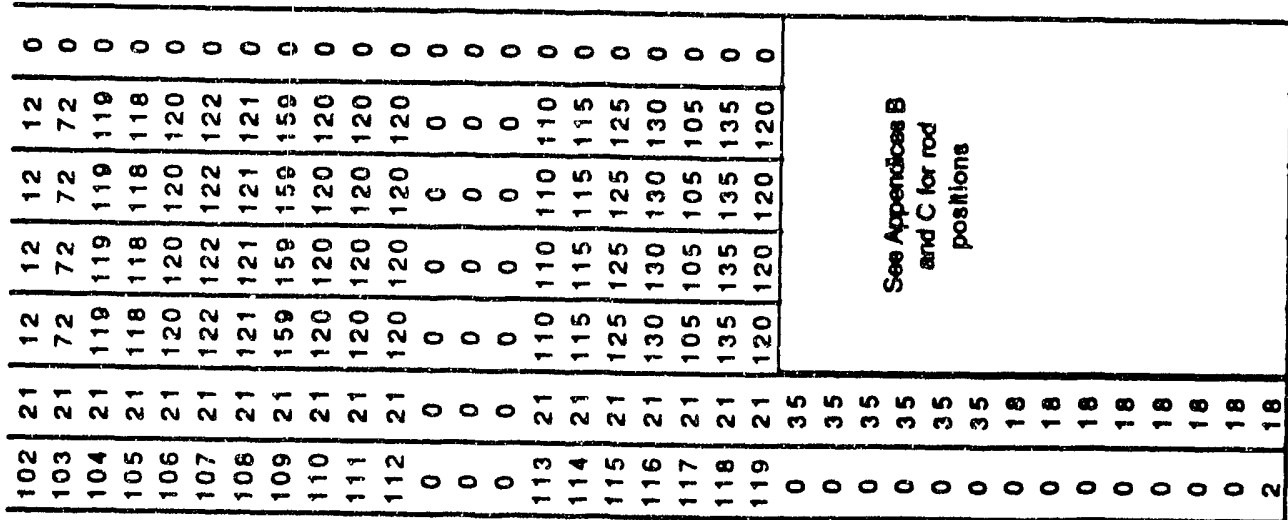


Table 3

Septifoil Leakage Test Matrix

- Modified Part Length Control Rods

run

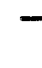

$240 \mathrm{~A}$

$240 \mathrm{~B}$

$241 \mathrm{~A}$

241B

$242 \mathrm{~A}$

242B

$243 \mathrm{~A}$

243B

$244 \mathrm{~A}$

$244 \mathrm{~B}$

$245 \mathrm{~A}$

$245 \mathrm{~B}$

$246 \mathrm{~A}$

246B

$247 \mathrm{~A}$

247B

$248 \mathrm{~A}$

248B

$249 \mathrm{~A}$

249B

$301 \mathrm{~A}$

$301 \mathrm{~B}$

$302 \mathrm{~A}$

$302 \mathrm{~B}$

$303 \mathrm{~A}$

$303 \mathrm{~B}$

$304 \mathrm{~A}$

$304 \mathrm{~B}$

$305 \mathrm{~A}$

$305 \mathrm{~B}$

$305 \mathrm{~A}$

$306 \mathrm{~B}$

$307 \mathrm{~A}$

$307 \mathrm{~B}$

$308 \mathrm{~A}$

$308 \mathrm{~B}$

$309 \mathrm{~A}$ flow PL rods $\operatorname{rod} G \operatorname{rod} 2(\mathrm{E})$ gpm

elev. inch inch inch

$$
\text { elev. }
$$

0

$\begin{array}{ll}106 & 0 \\ 120 & 0\end{array}$

106

120

105

120

106

120

106

120

106

120

106

120

106

120

106

12.0

100

120

106

120

106

120

106

120

106

120

106

120

106

120

106

120

106

120

106
0

0

0

0

0

0

0

0

0

$0 \quad 0$

$177 \quad 0$

1770

$177 \quad 177$

$177 \quad 177$

$177 \quad 177$

177

177

177

177

177

177

177

177

177

177

177

177

177

177

177

177

177

177

177

177

177

177

177

177

177

177

177

0

0

0

0

0

0

0

0

0

0

0

0

0

0

0
0

0
(B) $\operatorname{rod} 4(\mathrm{C}) \operatorname{rod} 5(\mathrm{~F})$ elev. elev. elev. inch inch inch

$\begin{array}{lll}0 & 0 & 0 \\ 0 & 0 & 0 \\ 0 & 0 & 0 \\ 0 & 0 & 0 \\ 0 & 0 & 0 \\ 0 & 0 & 0 \\ 0 & 0 & 0 \\ 0 & 0 & 0\end{array}$

$\begin{array}{lll}0 & 0 & 0\end{array}$

$\begin{array}{lll}0 & 0 & 0\end{array}$

0

0

0

0

177

177

177

177

177

177

0

0

0

0

0

0

0

0

0

0

0

0

0

0

0

0

0
0

0

0

0

0

0

0

0

0

0

0

0

$\begin{array}{ll}0 & 0 \\ 177 & 0\end{array}$

1770

$177 \quad 177$

$177 \quad 177$

$0 \quad 0$

$0 \quad 0$

2

2

4

4

6

6

8

8

10

10

12

12

14

14

16
0

2

4

4

6

6

8

8

10

10

12

12

14

14

16 
WSRC-TR-92-370

page 16

$\begin{array}{llllllll}\text { 309B } & 120 & 0 & 177 & 0 & 0 & 16 & 16 \\ \text { 310A } & 106 & 0 & 177 & 0 & 0 & 18 & 18 \\ 310 \mathrm{~B} & 120 & 0 & 177 & 0 & 0 & 18 & 18 \\ 311 \mathrm{~A} & 106 & 0 & 177 & 0 & 0 & 20 & 20 \\ 311 \mathrm{~B} & 120 & 0 & 177 & 0 & 0 & 20 & 20 \\ 312 \mathrm{~A} & 106 & 0 & 177 & 0 & 0 & 22 & 22 \\ 312 \mathrm{~B} & 120 & 0 & 177 & 0 & 0 & 22 & 22 \\ 313 \mathrm{~A} & 106 & 0 & 177 & 0 & 0 & 24 & 24 \\ 313 \mathrm{~B} & 120 & 0 & 177 & 0 & 0 & 24 & 24 \\ 314 \mathrm{~A} & 106 & 0 & 177 & 0 & 0 & 26 & 26 \\ 314 \mathrm{~B} & 120 & 0 & 177 & 0 & 0 & 26 & 26 \\ 315 \mathrm{~A} & 106 & 0 & 177 & 0 & 0 & 28 & 28 \\ 315 \mathrm{~B} & 120 & 0 & 177 & 0 & 0 & 28 & 28 \\ 316 \mathrm{~A} & 106 & 0 & 177 & 0 & 0 & 30 & 30 \\ 316 \mathrm{~B} & 120 & 0 & 177 & 0 & 0 & 30 & 30 \\ 317 \mathrm{~A} & 106 & 0 & 177 & 0 & 0 & 32 & 32 \\ 317 \mathrm{~B} & 120 & 0 & 177 & 0 & 0 & 32 & 32 \\ 318 \mathrm{~A} & 106 & 0 & 177 & 0 & 0 & 34 & 34 \\ 318 \mathrm{~B} & 120 & 0 & 177 & 0 & 0 & 34 & 34 \\ 319 \mathrm{~A} & 106 & 0 & 177 & 0 & 0 & 36 & 36 \\ 319 \mathrm{~B} & 120 & 0 & 177 & 0 & 0 & 36 & 36 \\ \text { 400A } & 106 & 36 & 168 & 168 & 168 & 168 & 168 \\ \text { 400B } & 120 & 36 & 168 & 168 & 168 & 168 & 168\end{array}$




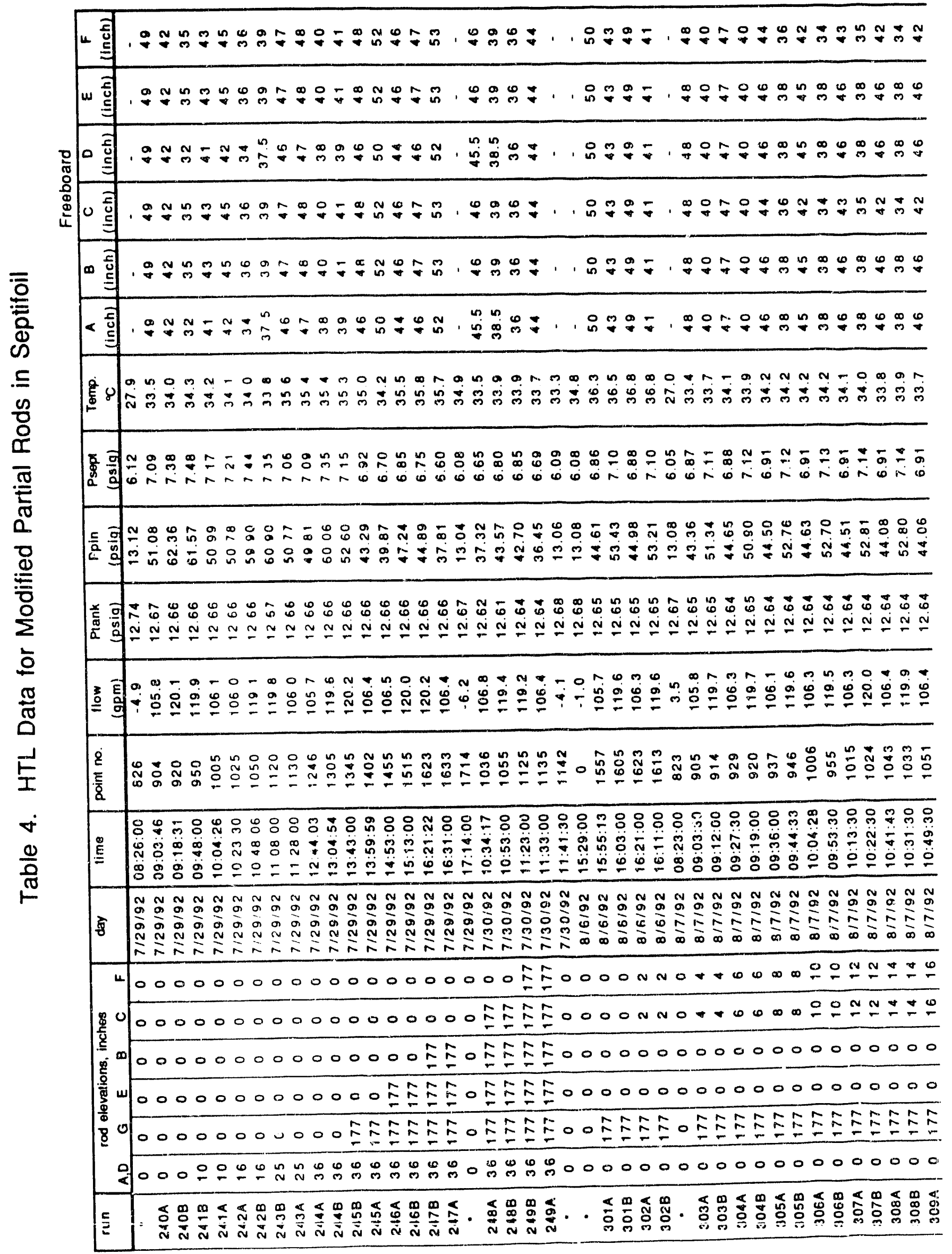




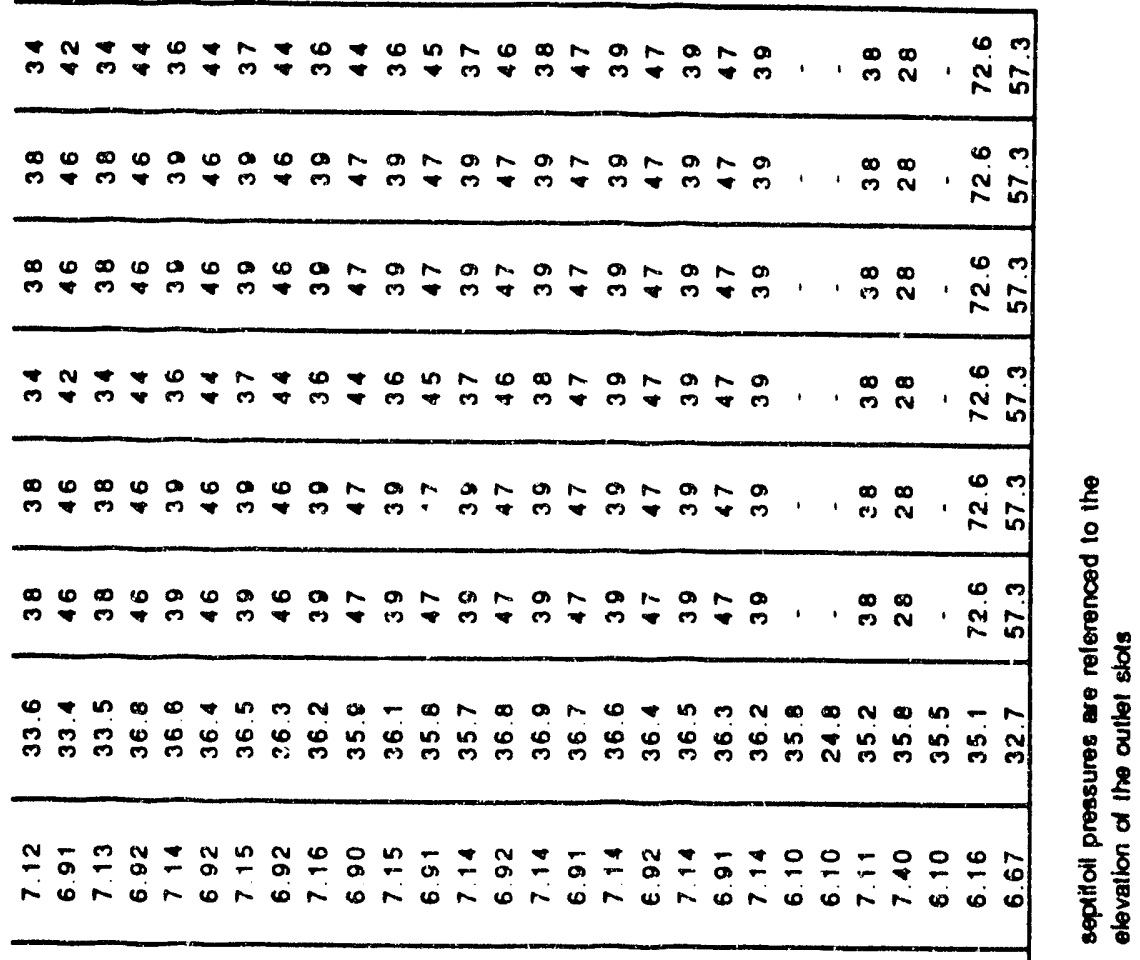

芦每 กี

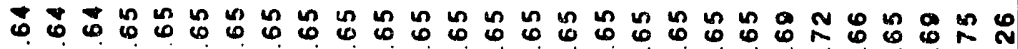

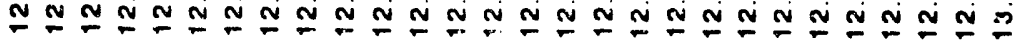

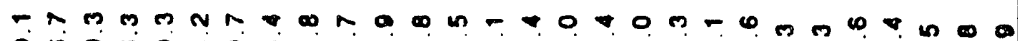

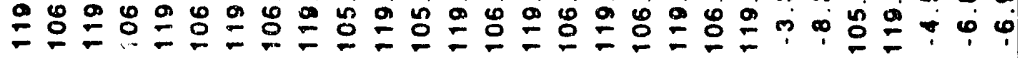

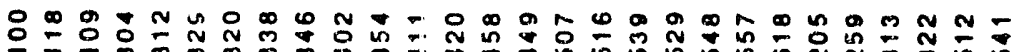

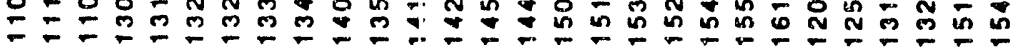

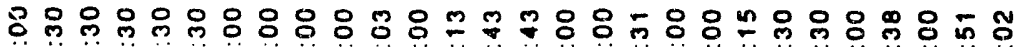

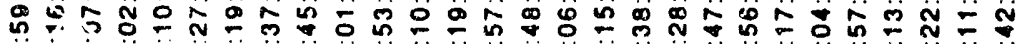

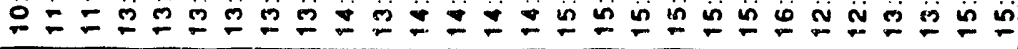

\

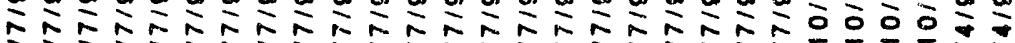

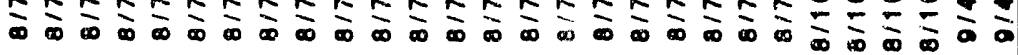
묘유 ㅇN N

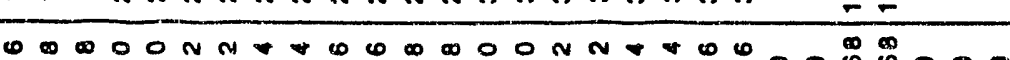

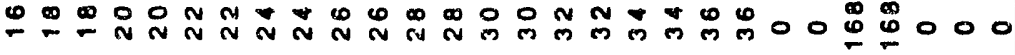
$00000000000000000000000 \$ 0000$ $00000000000000000000000 \$ 0000$

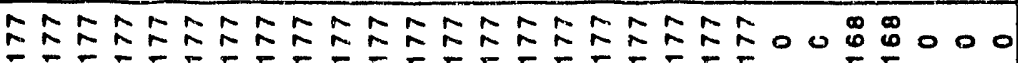
$000000000000000000000000 \% 000$

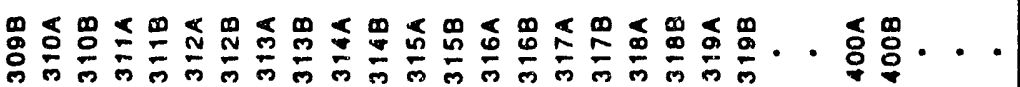




\begin{tabular}{|c|c|}
\hline ․ㅗㅇㅝ & 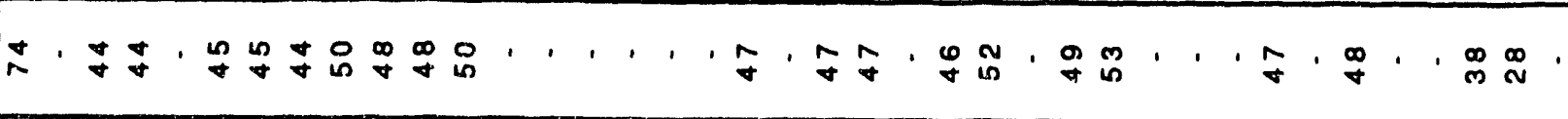 \\
\hline 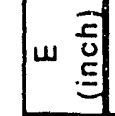 & 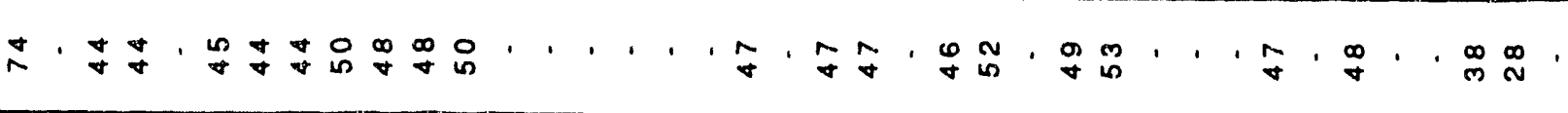 \\
\hline ○ & 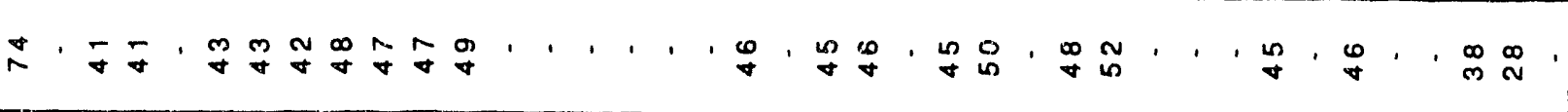 \\
\hline \begin{tabular}{ll|l} 
& 0 \\
\hdashline & 0 \\
\end{tabular} & 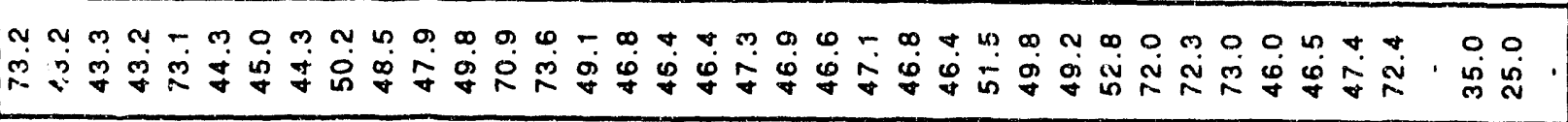 \\
\hline$\infty$ 氞 & 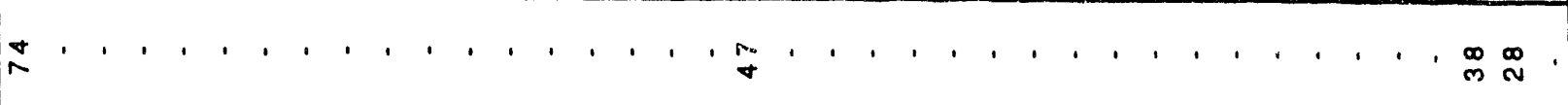 \\
\hline \& & M \\
\hline 递 8 & 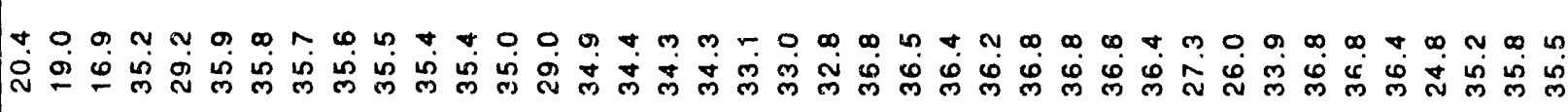 \\
\hline $\mid \begin{array}{cc}0 \\
0 \\
0\end{array}$ & 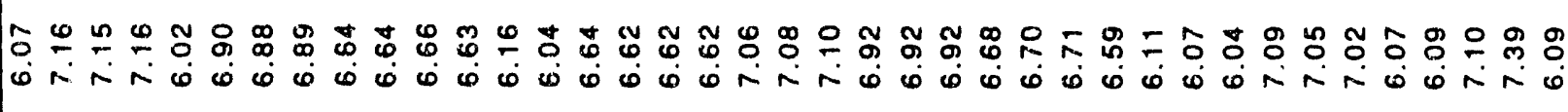 \\
\hline$\div$ 영 & 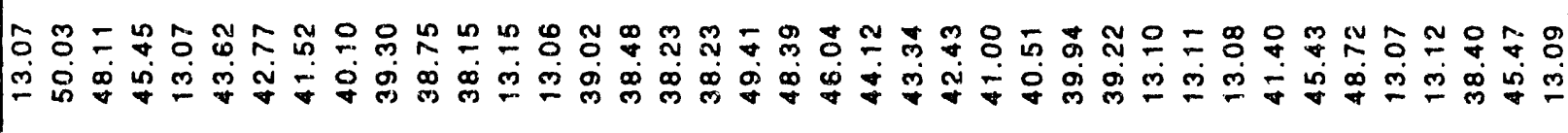 \\
\hline 辳 & 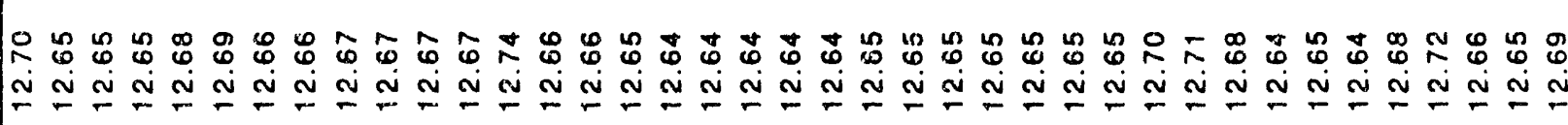 \\
\hline 영 & 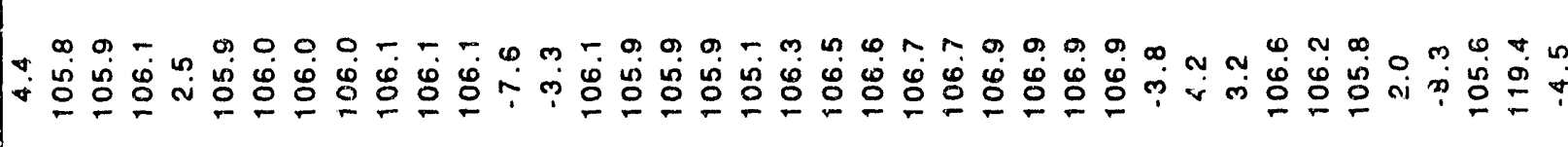 \\
\hline$\frac{\dot{2}}{\dot{\underline{L}}}$ & 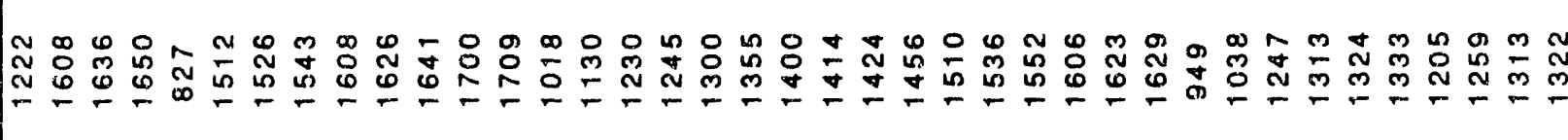 \\
\hline$\stackrel{\mathscr{ٌ}}{\underline{\Xi}}$ & 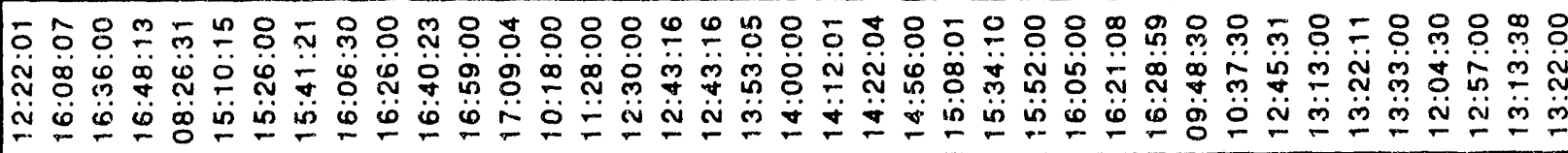 \\
\hline 항 & 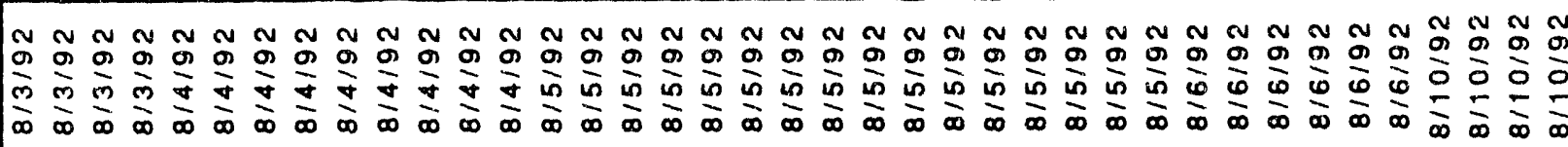 \\
\hline
\end{tabular}


20

Figure 1

Side View of Type $Q$ Septifoil in Reactor

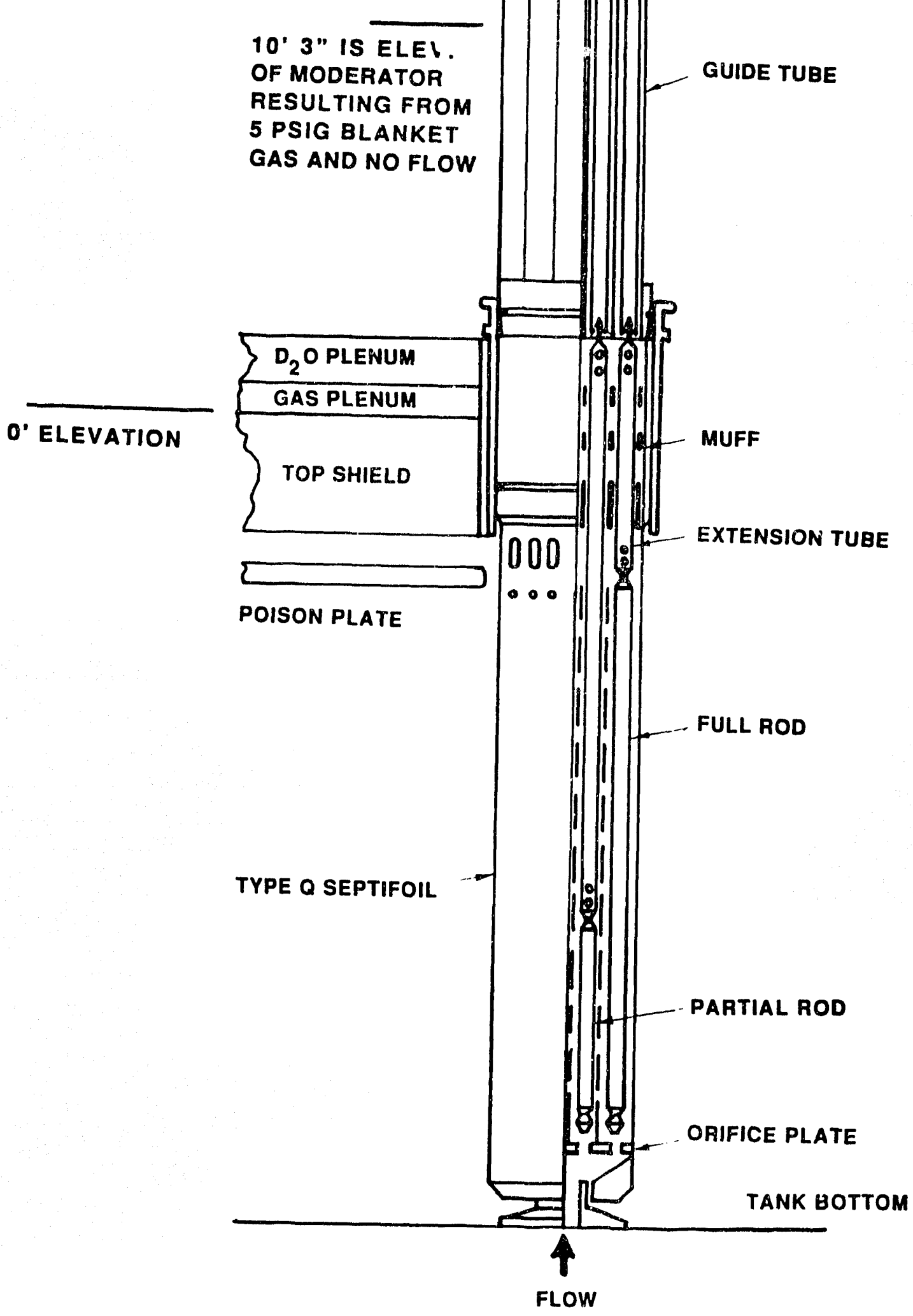


Figure 2

Full and Partial Length Lithium Control Rods

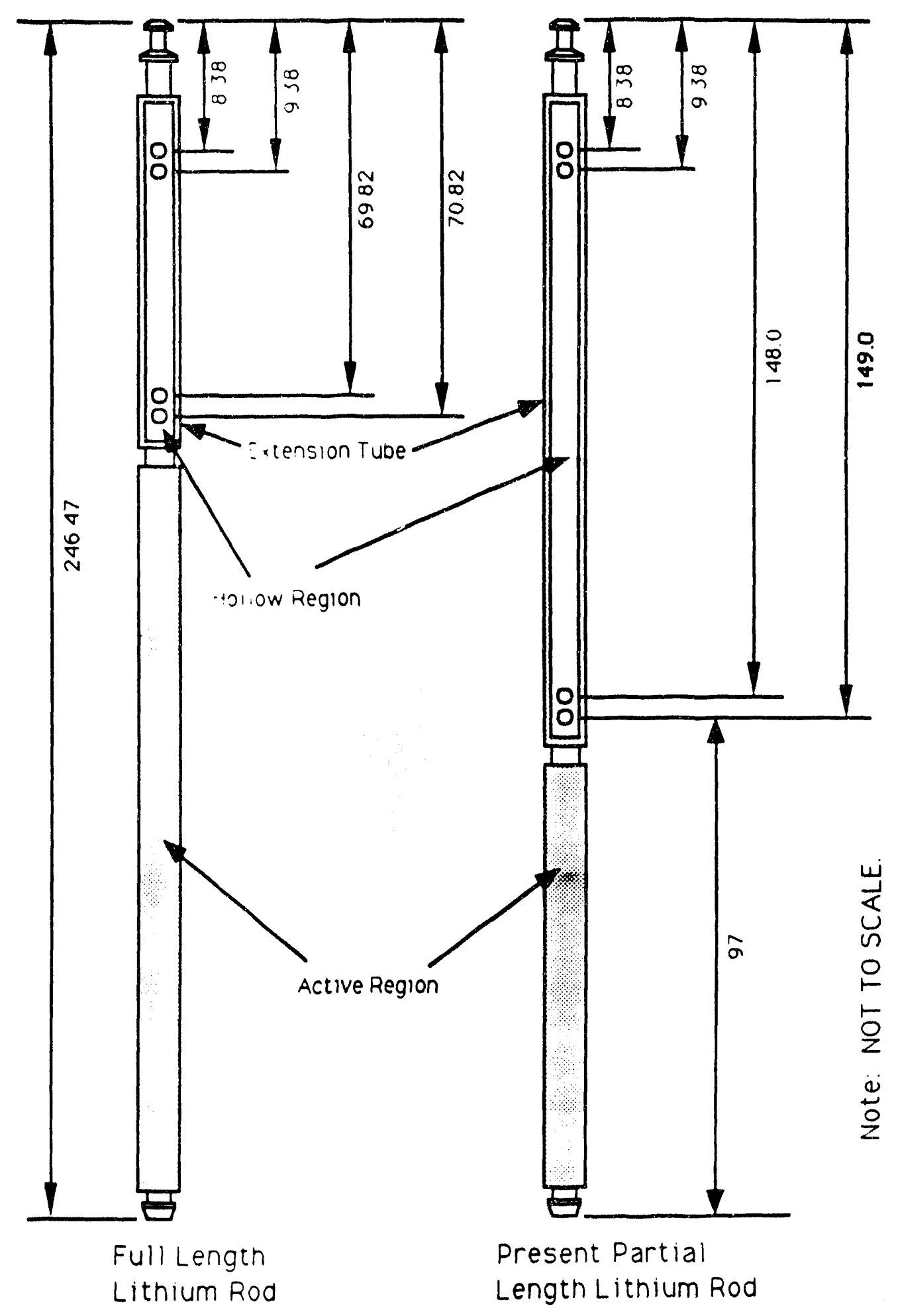


Figure 3

Modified Partial Control Rod and Cadmium Control Rod

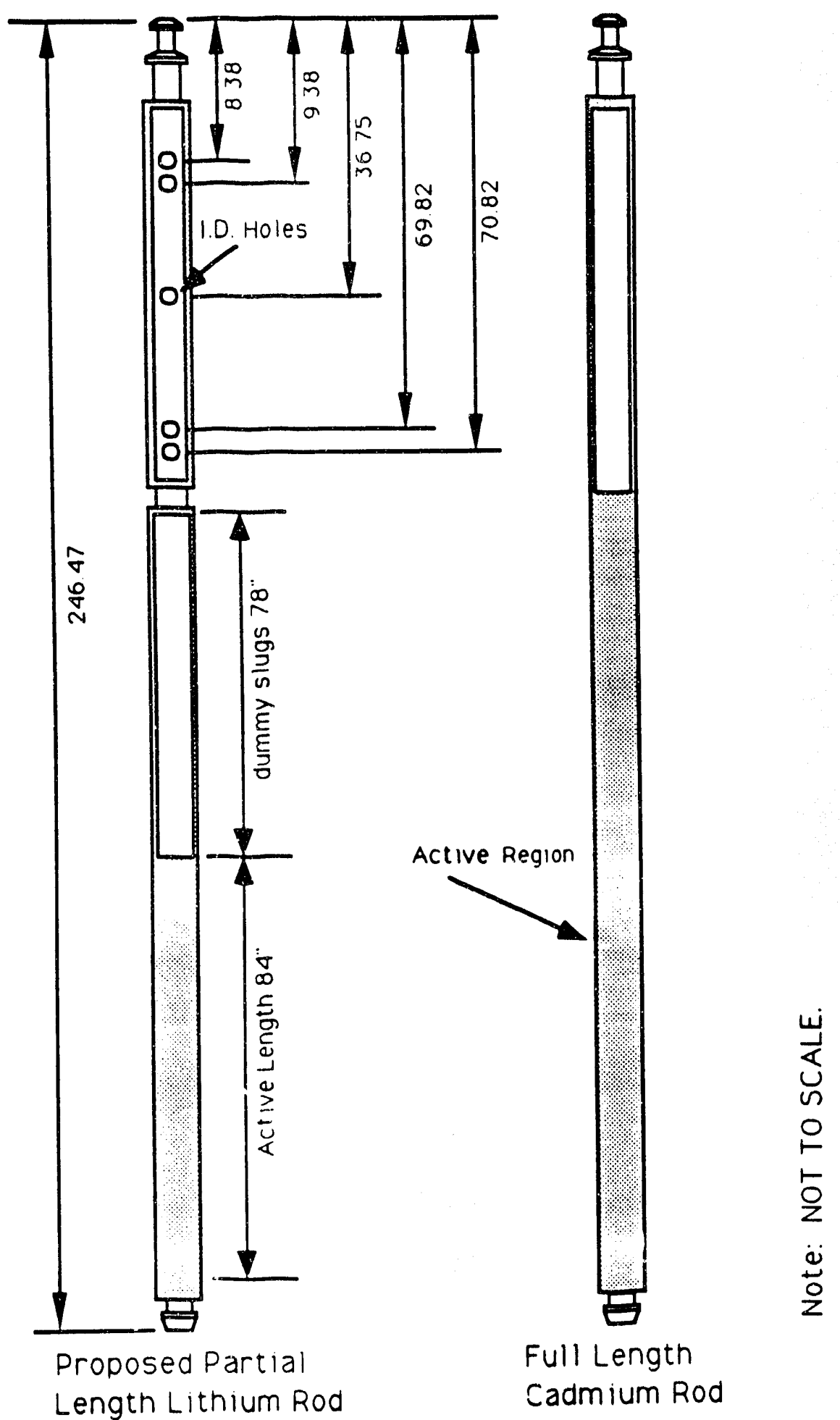


Figure 4

Source Rod

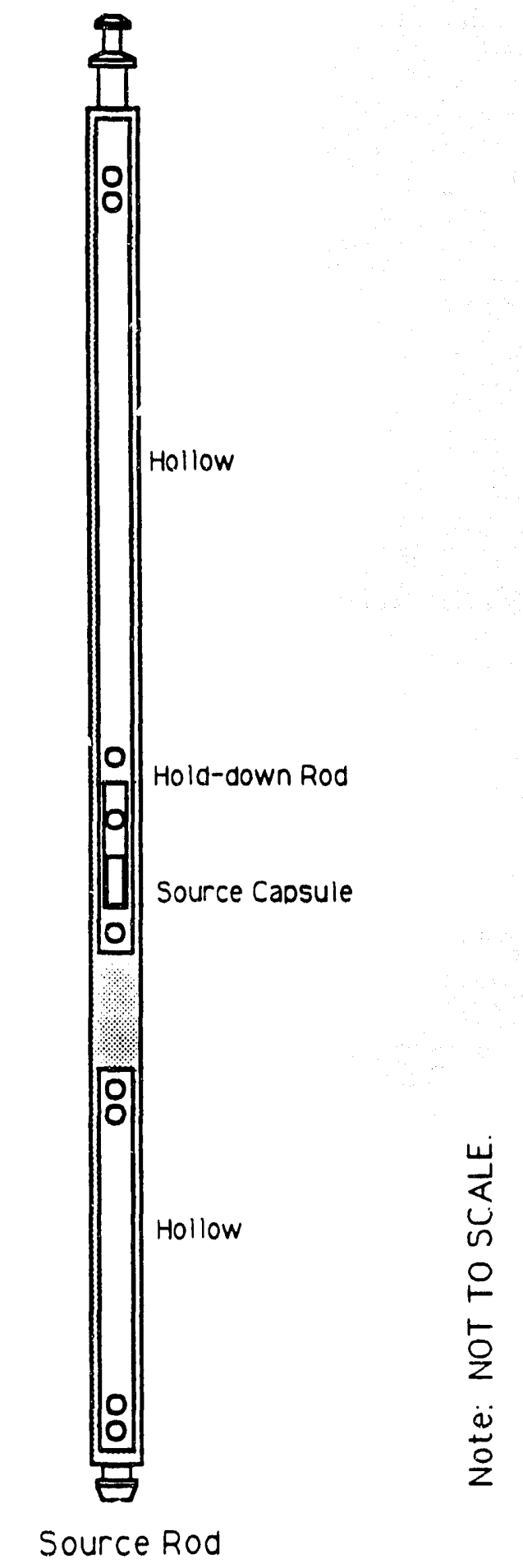


Figure 5. Schematic of Modified Long Term Flow Facility

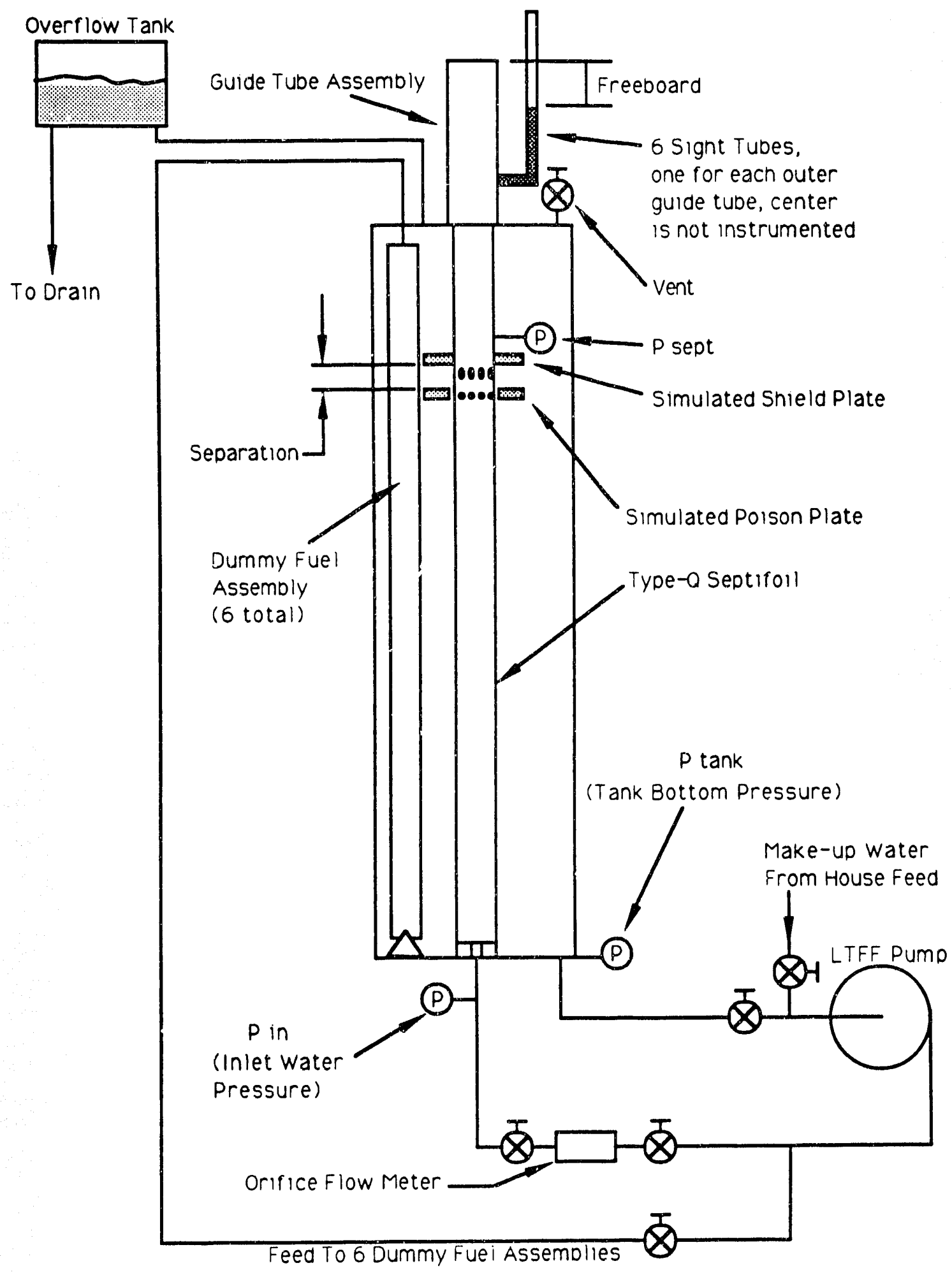


Figure 6. Positions of Control Rods in Septifoil.

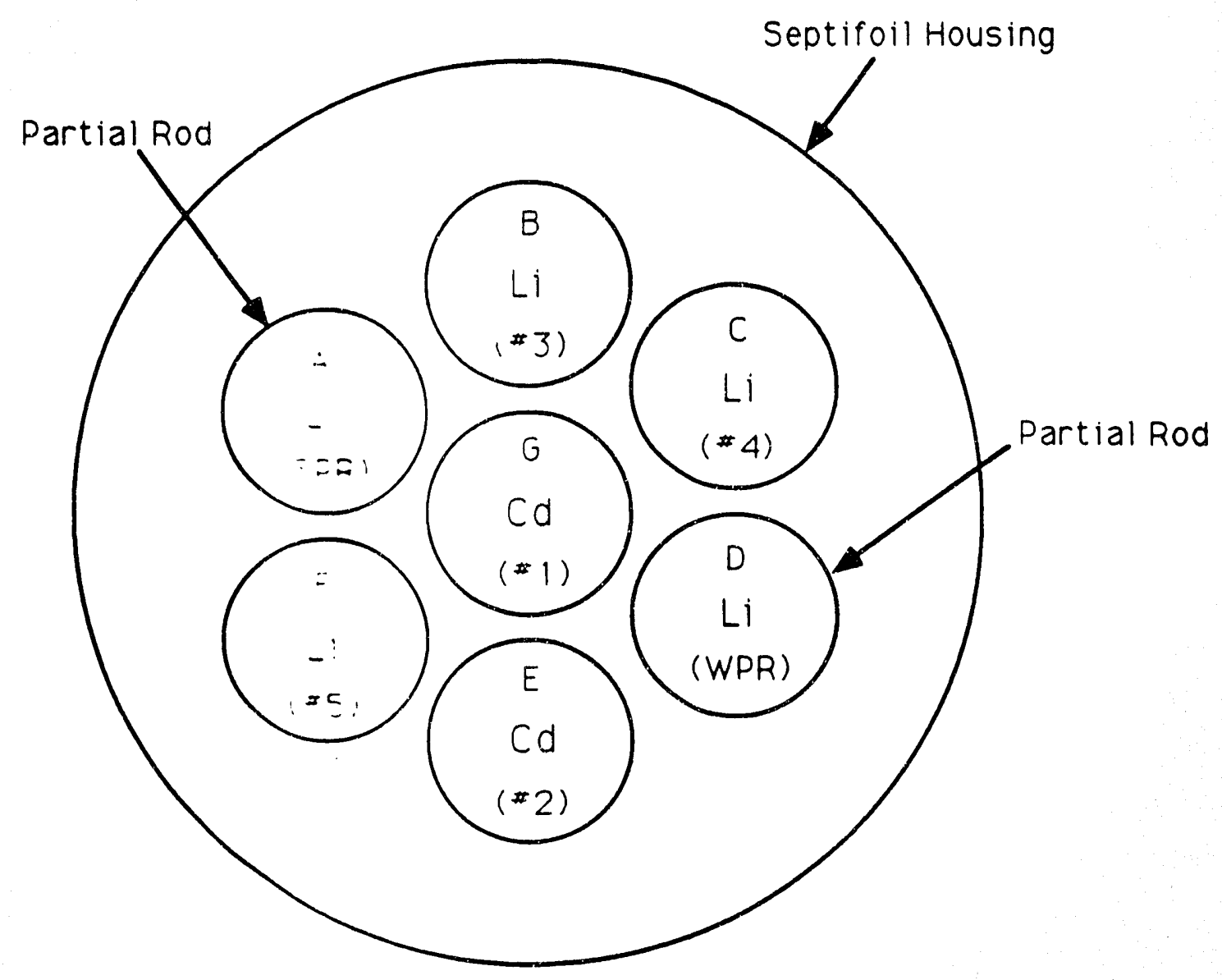




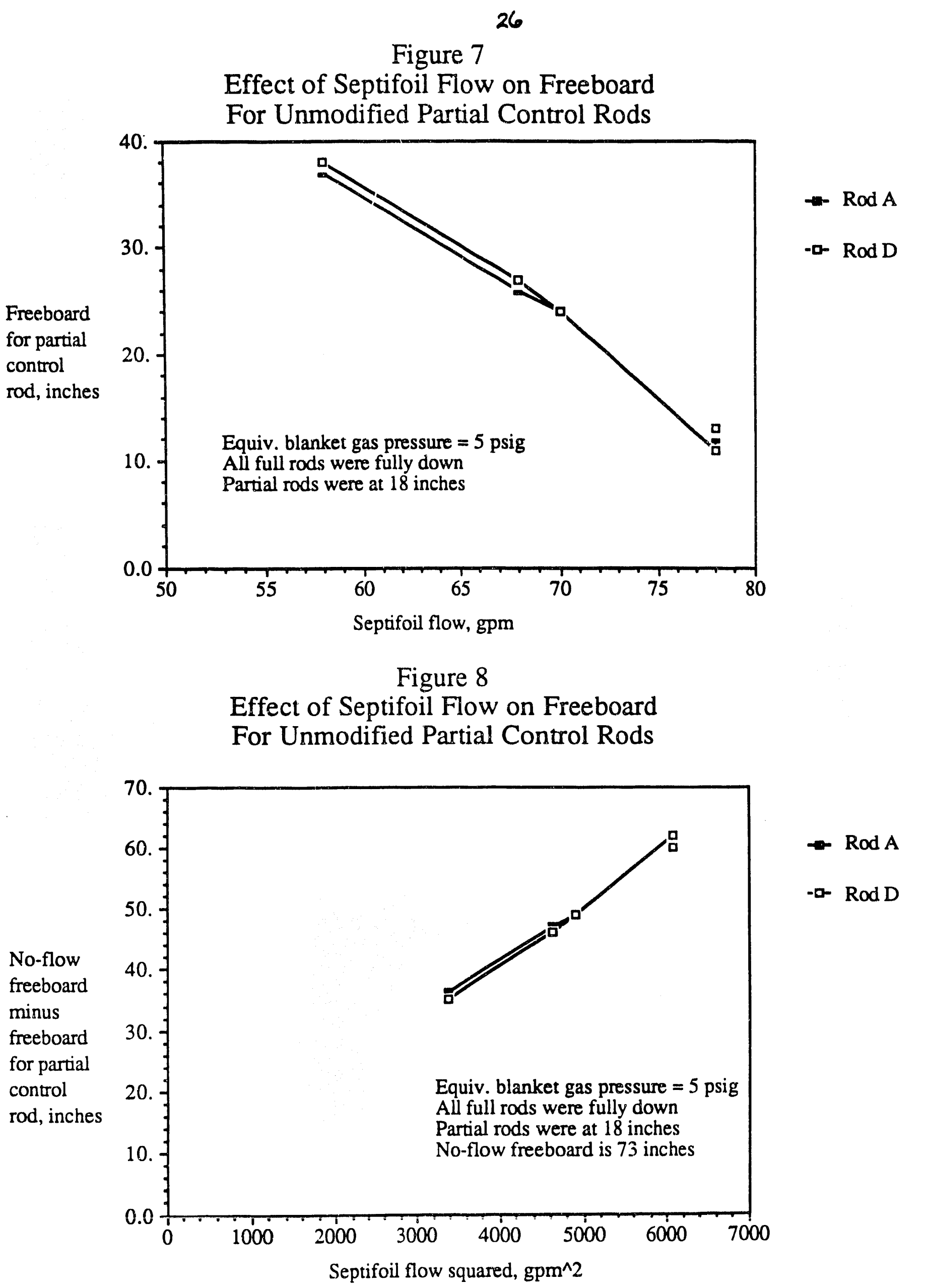


Figure 9

Effect of Partial Rod Elevation on Freeboard, $68 \mathrm{gpm}$ For Unmodified Partial Control Rods

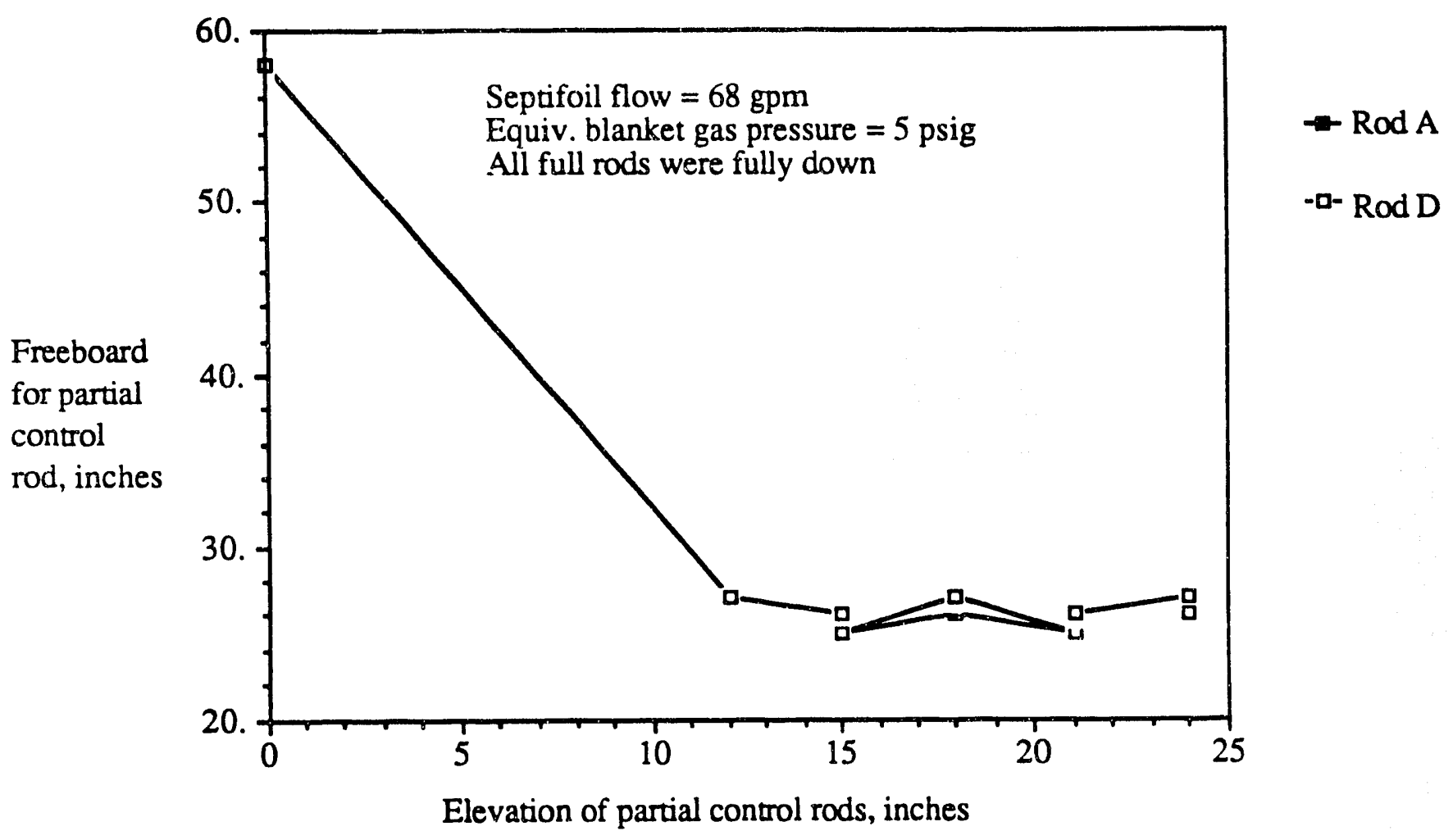


Figure 10

Effect of Full Rod Elevation on Freeboard, 68 gpm For Unmodified Partial Control Rods

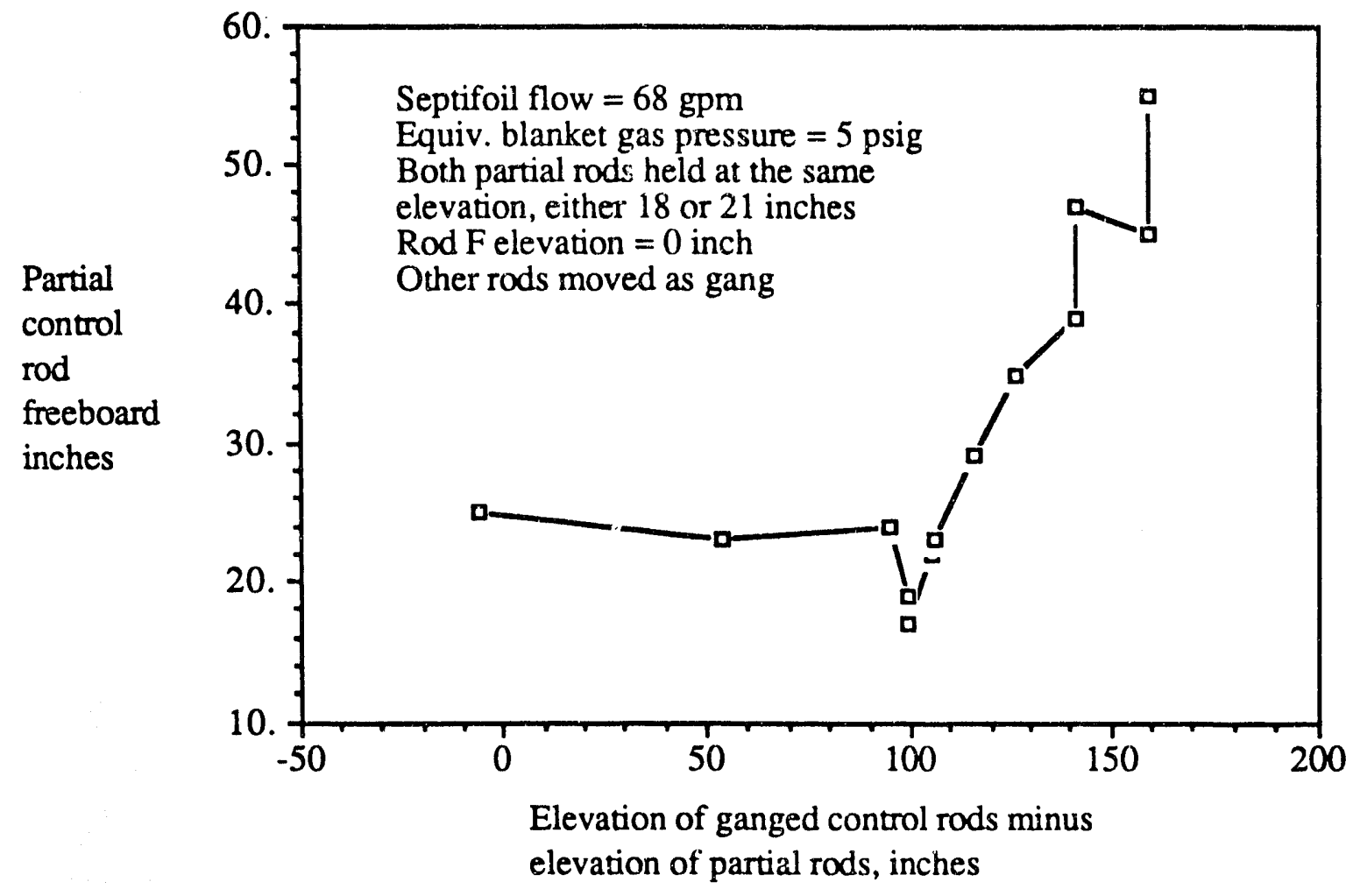

Figure 11

Effect of Full Rod Elevation on Freeboard, 70 gpm For Unmodified Partial Control Rods

Partial

control

$\operatorname{rod}$

freeboard inches

Septifoil flow $=70 \mathrm{gpm}$

50
40

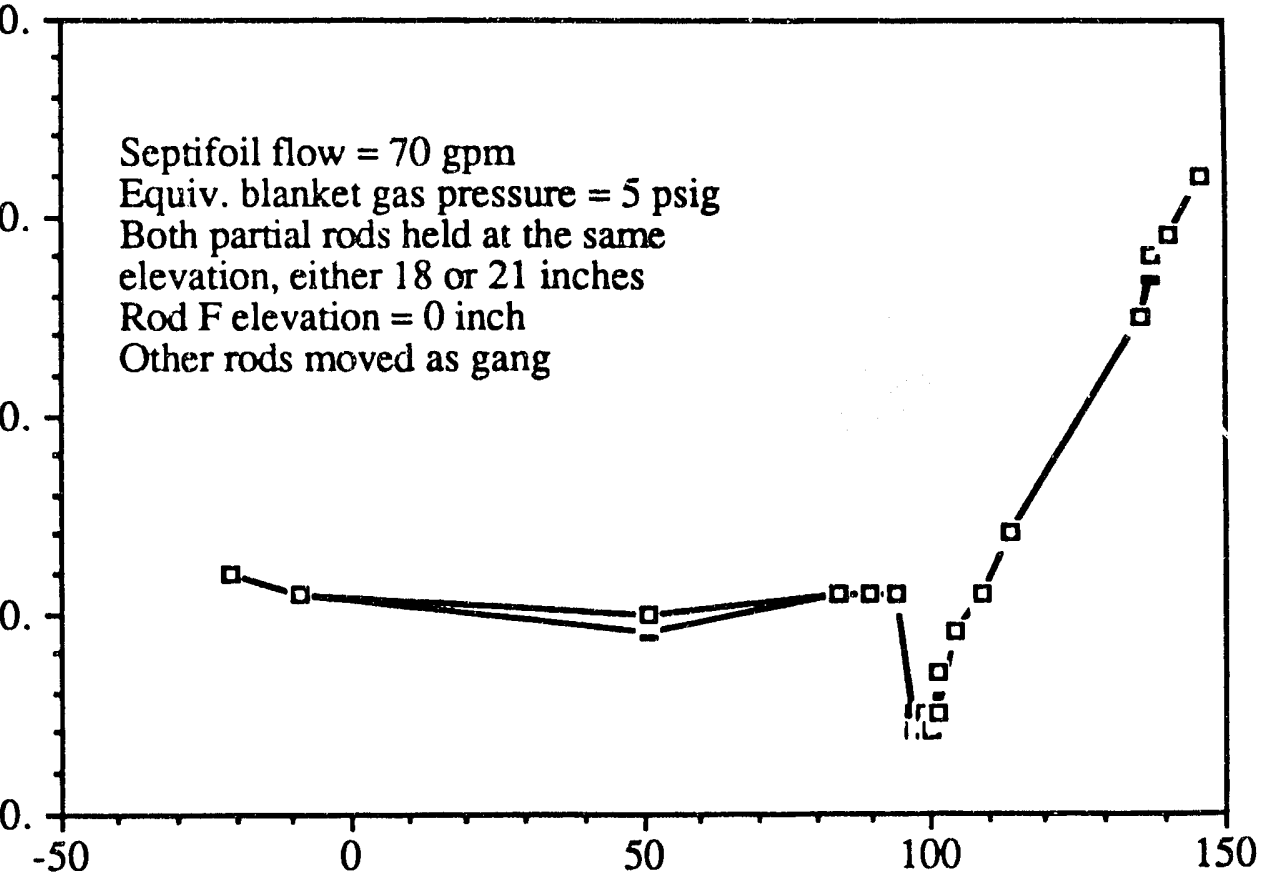

$\operatorname{Rod} \mathrm{A}$

$-0-\operatorname{Rod} D$

Elevation of ganged control rods minus elevation of partial rods, inches 
Figure 12

\section{Effect of Modified Partial Rod Withdrawal on Freeboard All Full Length Control Rods Fully In}

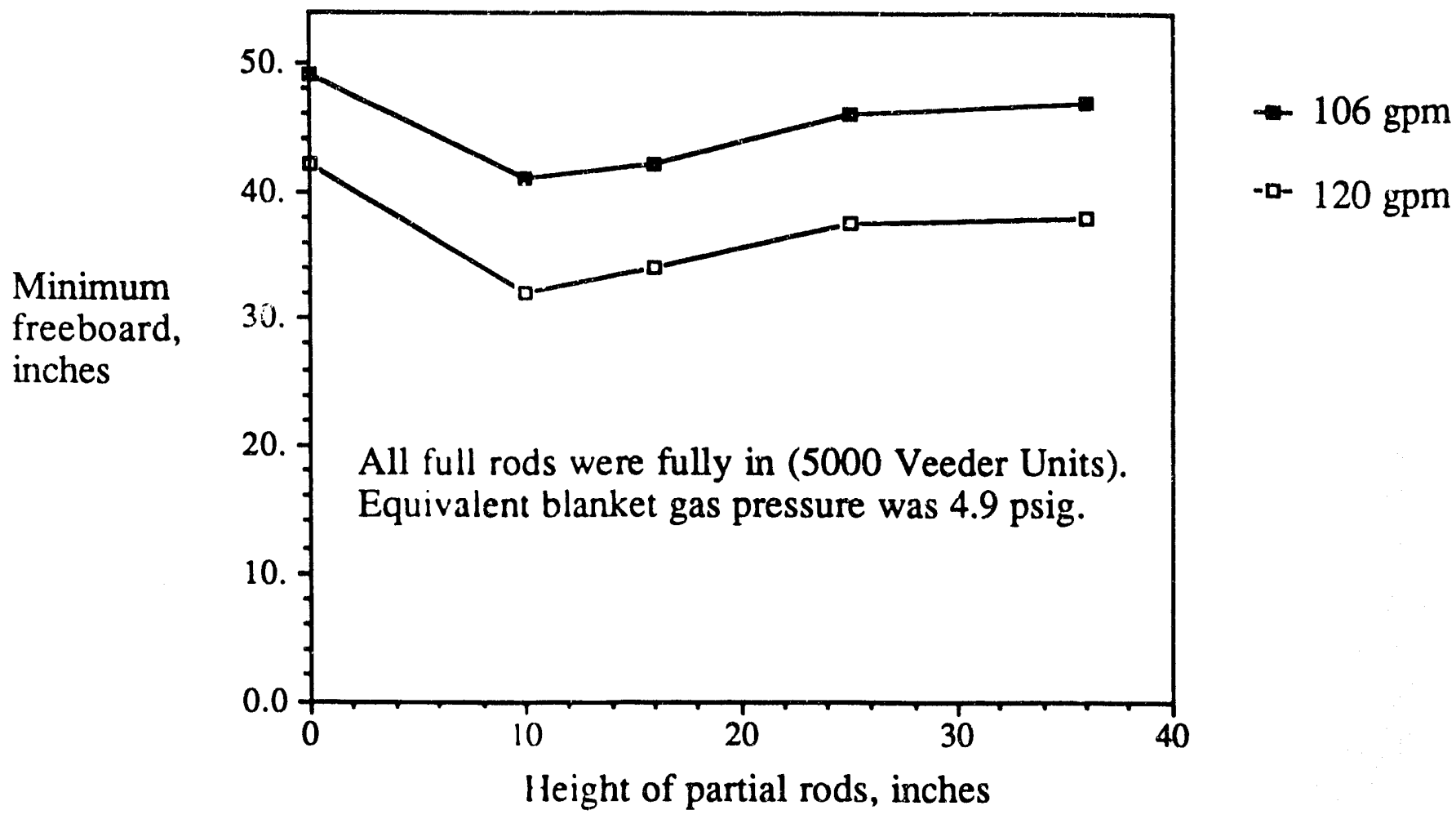

Figure 13

Effect of Full Rod Withdrawal on Freeboard, 106 and 120 gpm

- Modified Part Length Control Rod at 36"

Minimum

freeboard, inches

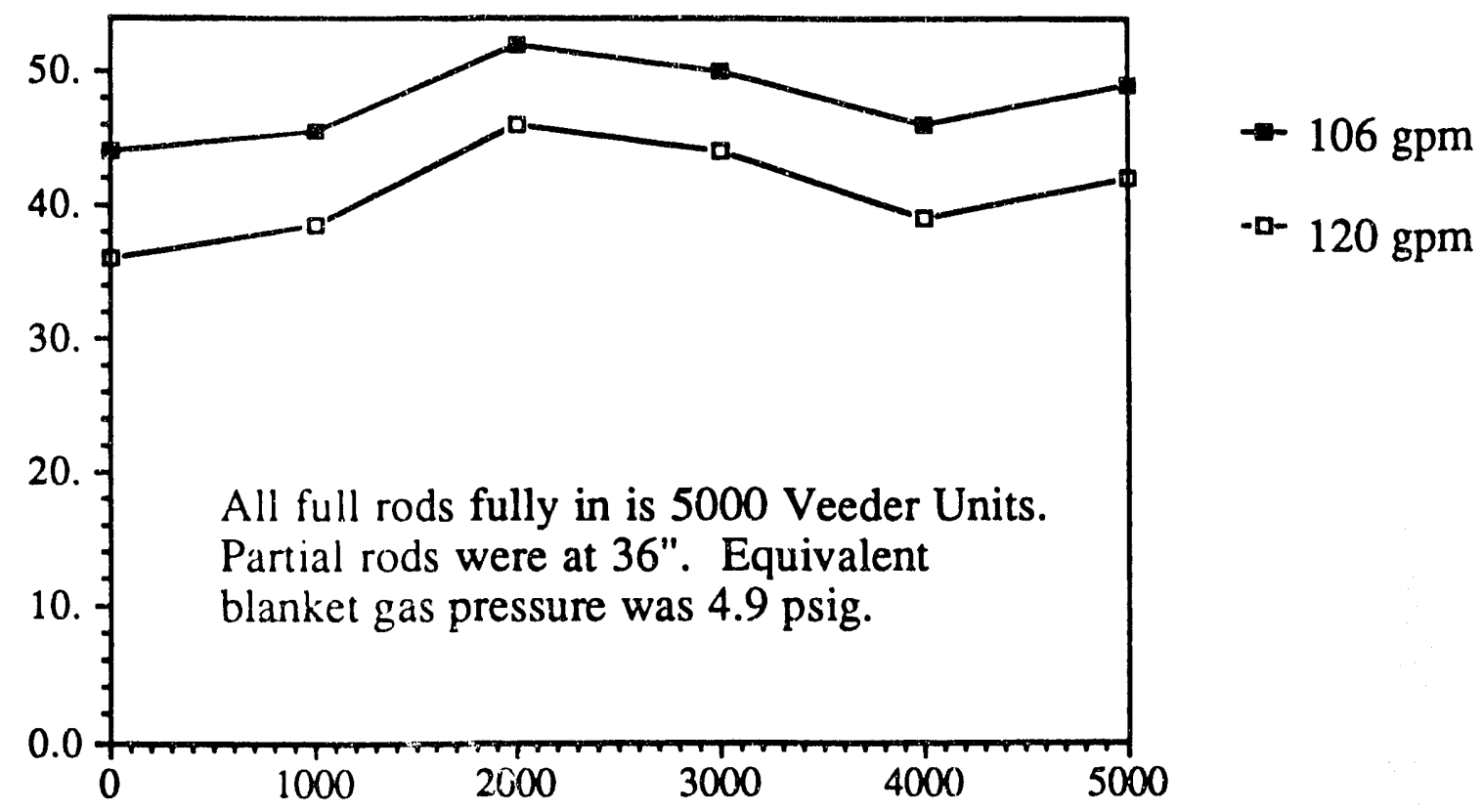

Fuii rod withdàrawai, veeder units 
Figure 14

Freeboard as Modified Partial

Control Rods Are Pulled

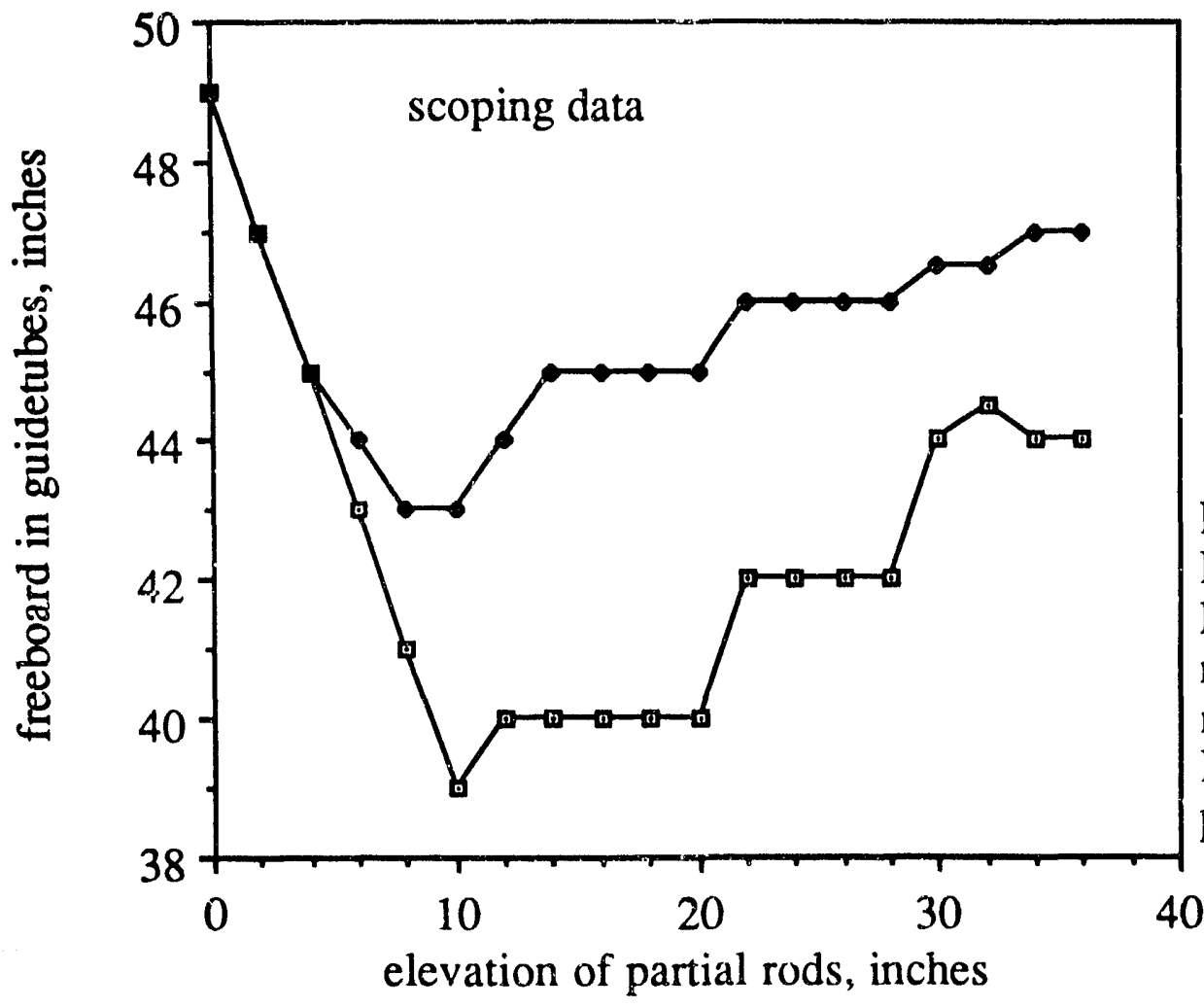

guidetube

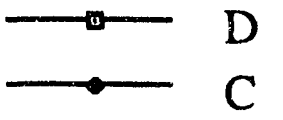

Flow $=106$ gpm

Partial rods $A$ and $D$ lifted sogether. $G$ rod out. Other rods were fully down. Equiv. blanket gas pressure $=4.9 \mathrm{psig}$

Figure 15

Freeboard As C and F Control Rods Are Pulled Modified Partial Rods Are Fully In

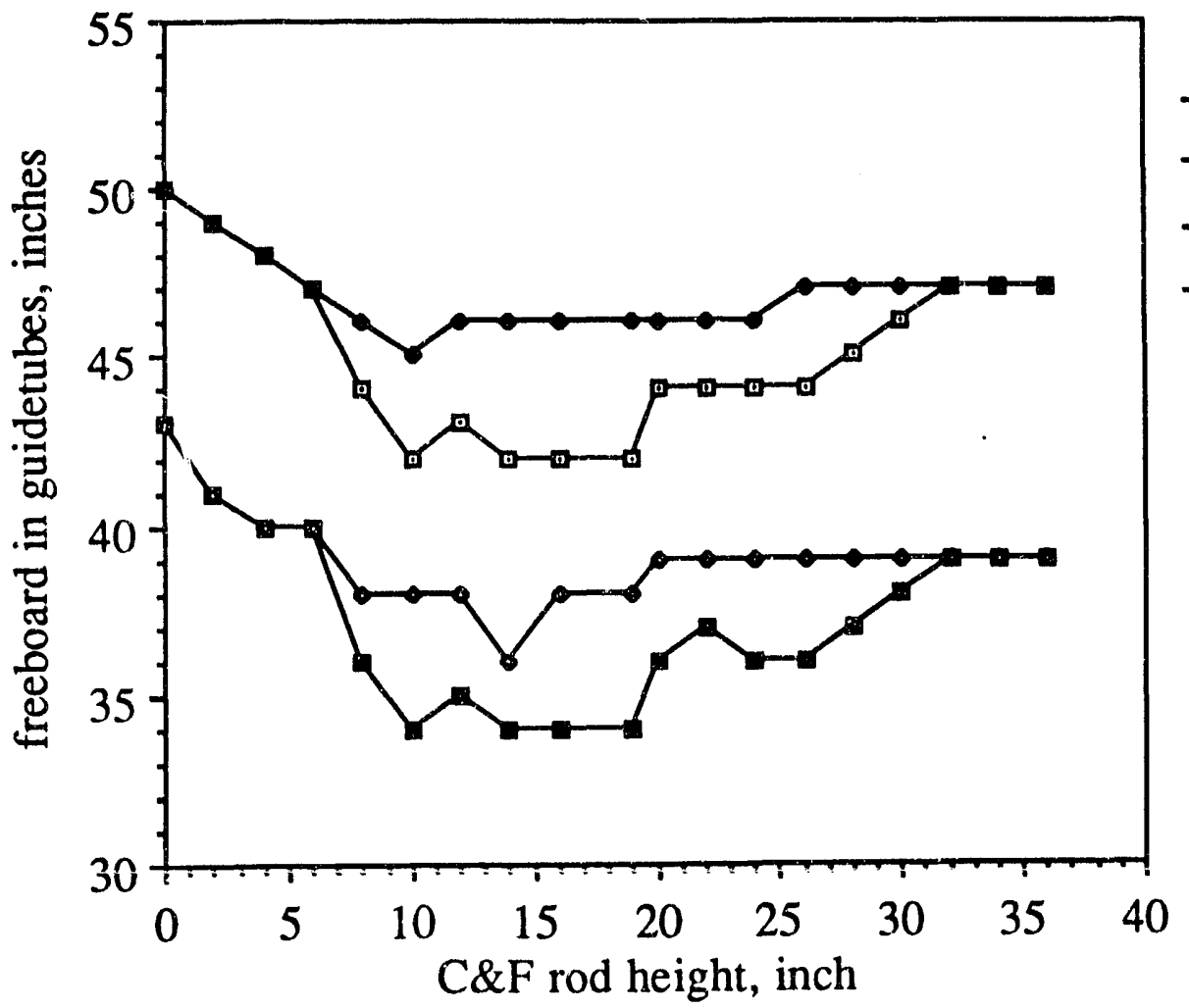

Rods C\&F were lifted together. G rod out. Other rods were fully down. Equivalent blanket gas

pressure 4.9 psig.

- $106 \mathrm{gpm}, \mathrm{C} \& \mathrm{~F}$ rods

$106 \mathrm{gpm}$, other rods

$\longrightarrow \quad 120 \mathrm{gpm}, \mathrm{C} \& \mathrm{~F}$ rods

$\longrightarrow 120 \mathrm{gpm}$, other rods 
Figure 16

Freeboard Transient as Three Control Rods Are Lifted in Sequence and Then All Three Rods Are Scrammed 106 gpm, 5.0 psig Blanket Gas

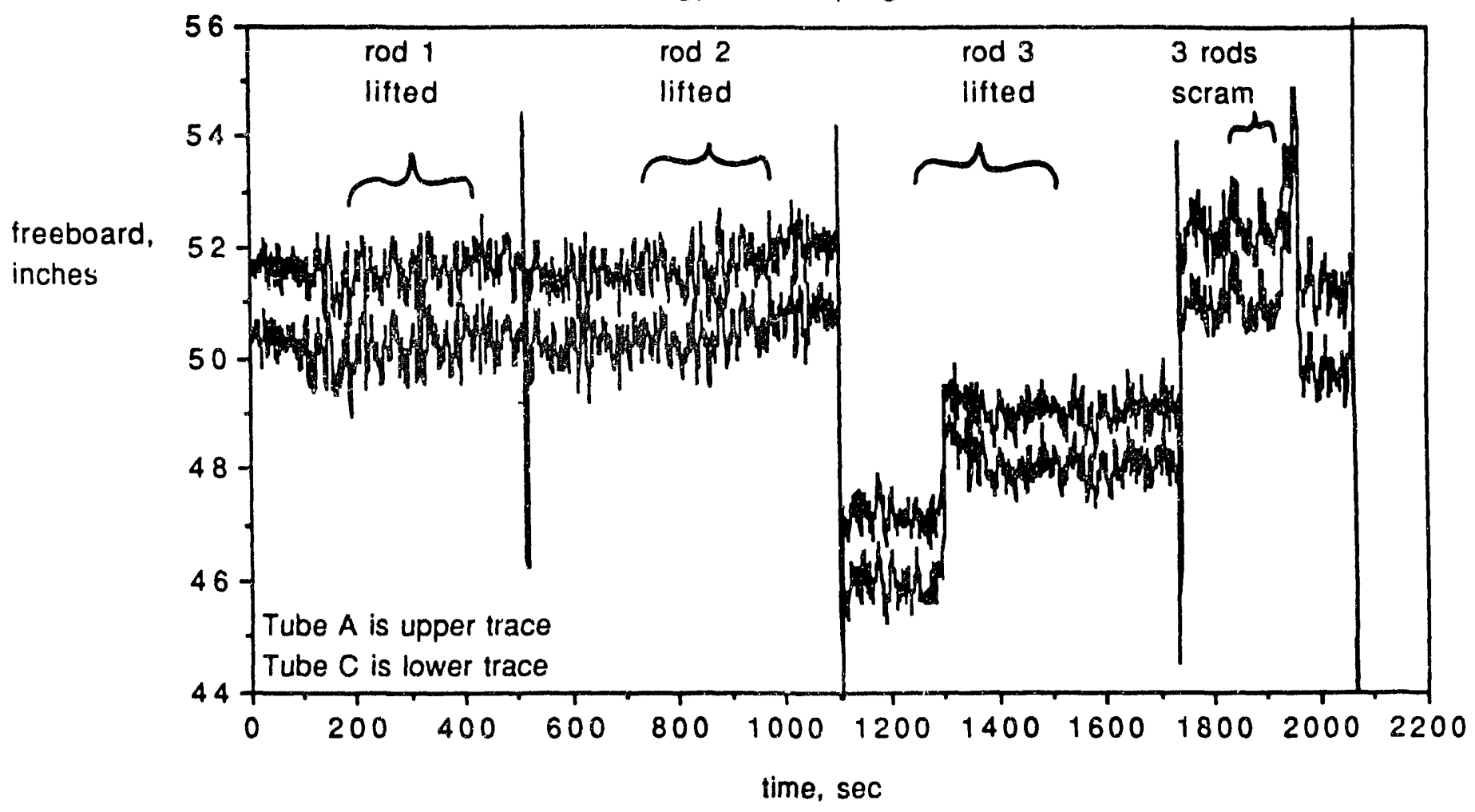

Figure 17

Freeboard Transient as Three Control Rods Are Lifted in Sequence and Then All Three Rods Are Scrammed $106 \mathrm{gpm}, 5.0$ psig Blanket Gas

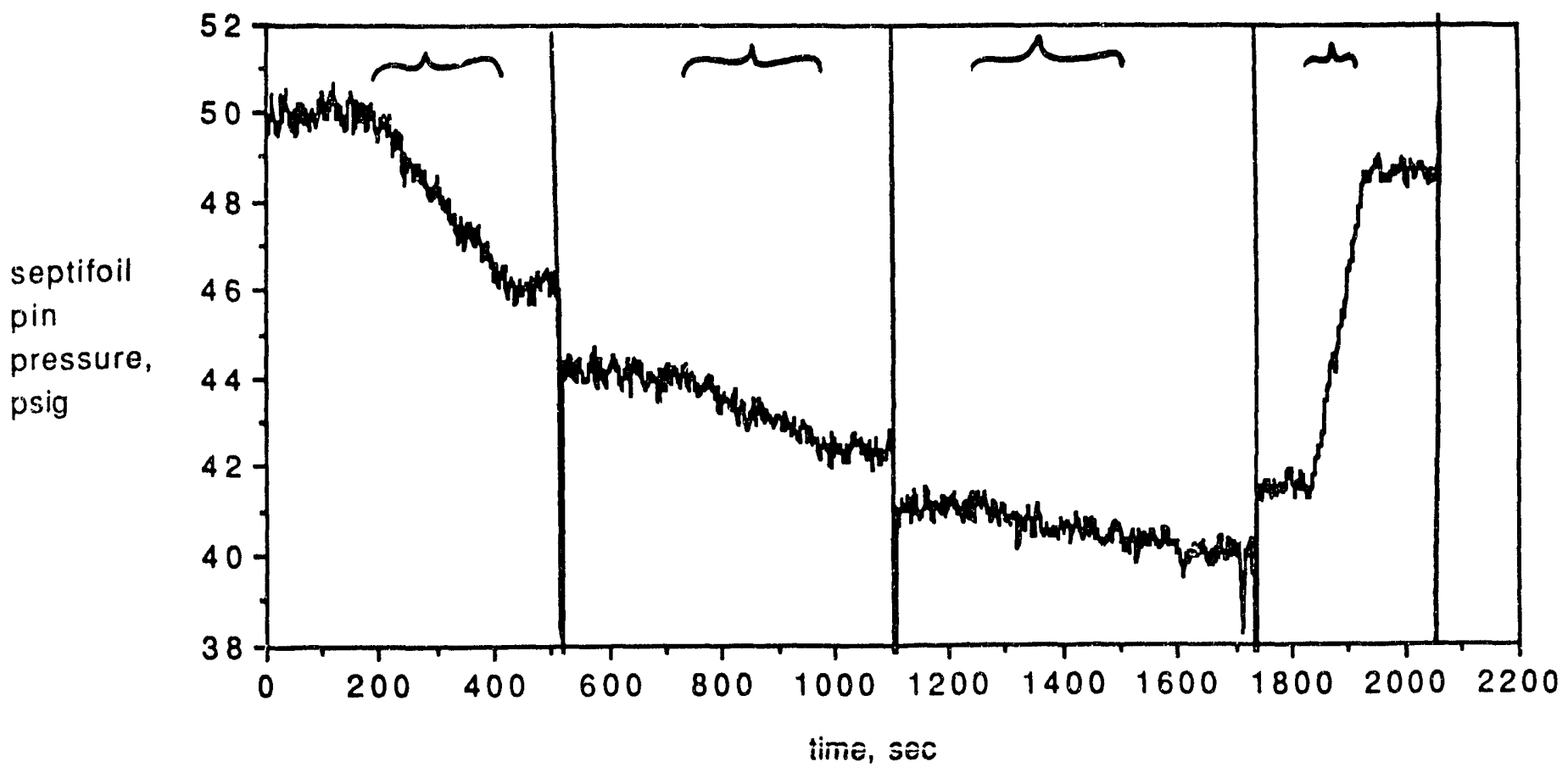


Figure 18

32

Freeboard Transient as One Control Rods is Lifted and

Four Rods Are Scrammed, 106 gpm, 5.0 psig Blanket Gas

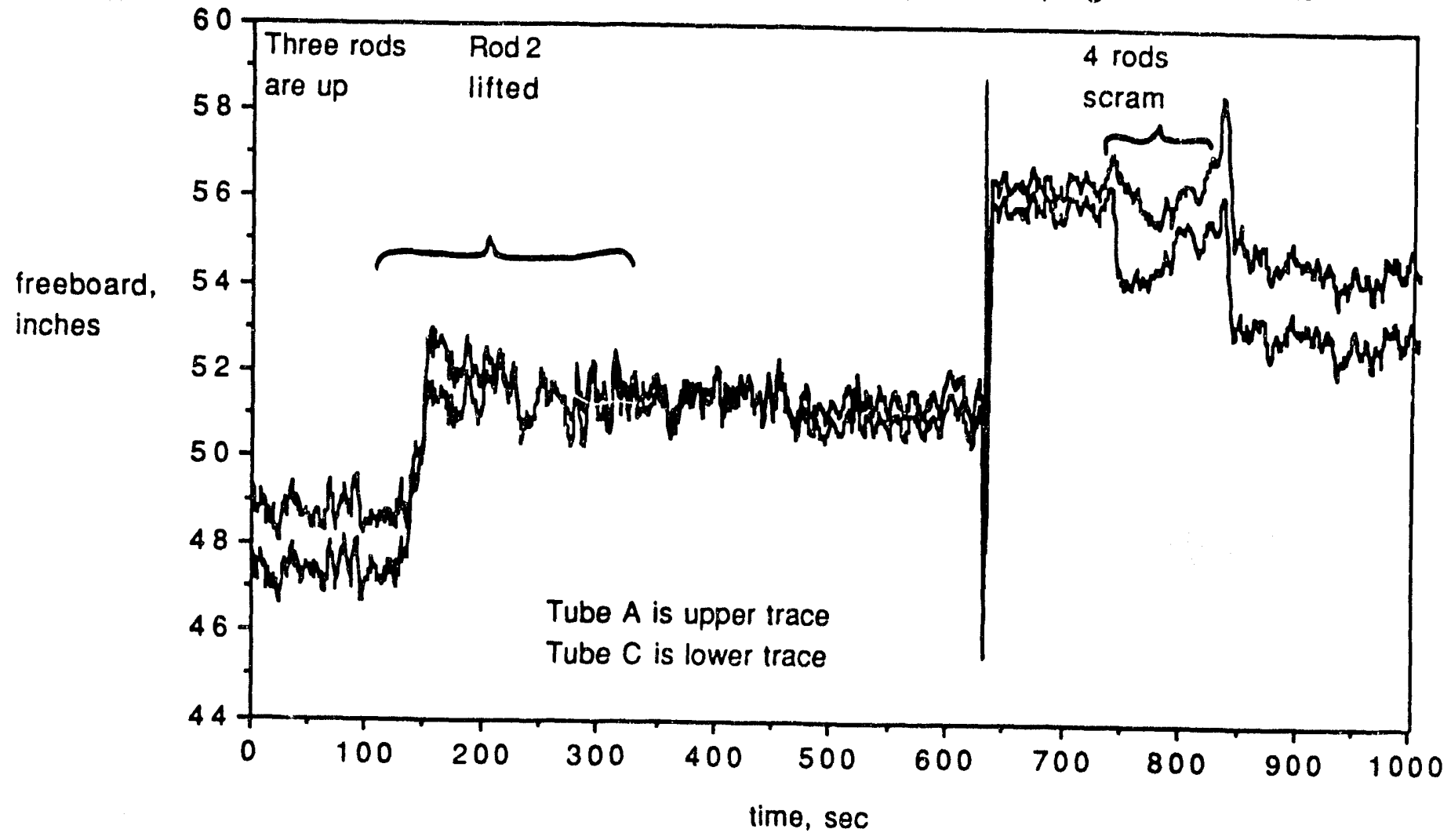

Figure 19

Pin Pressure Transient as One Control Rods Is Lifted and Four Rods Are Scrammed, 106 gpm, 5 psig Blanket Gas

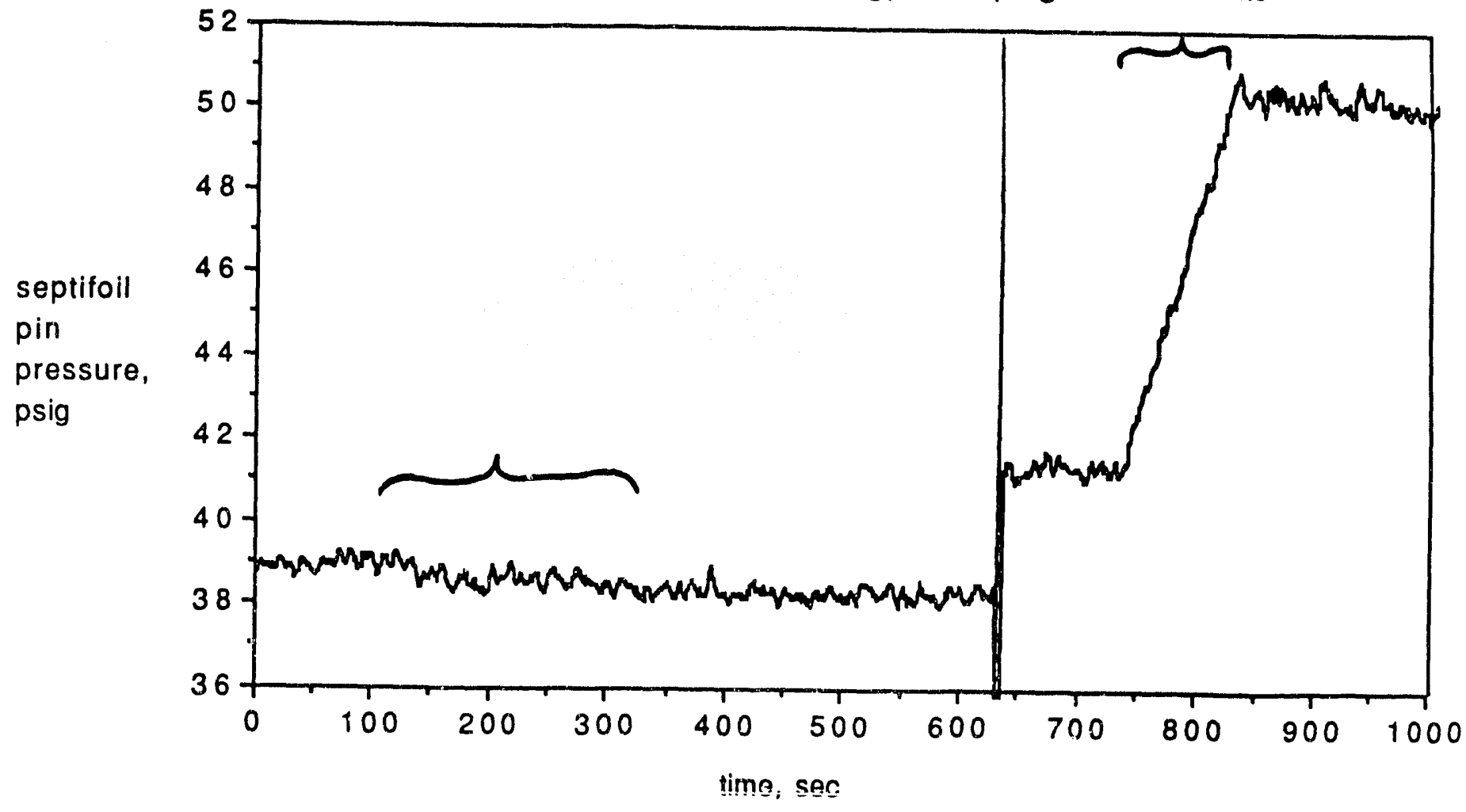


Figure 20

Freeboard Transient as Five Control Rods are

Scrammed, 106 gpm, 5.0 psig Blanket Gas

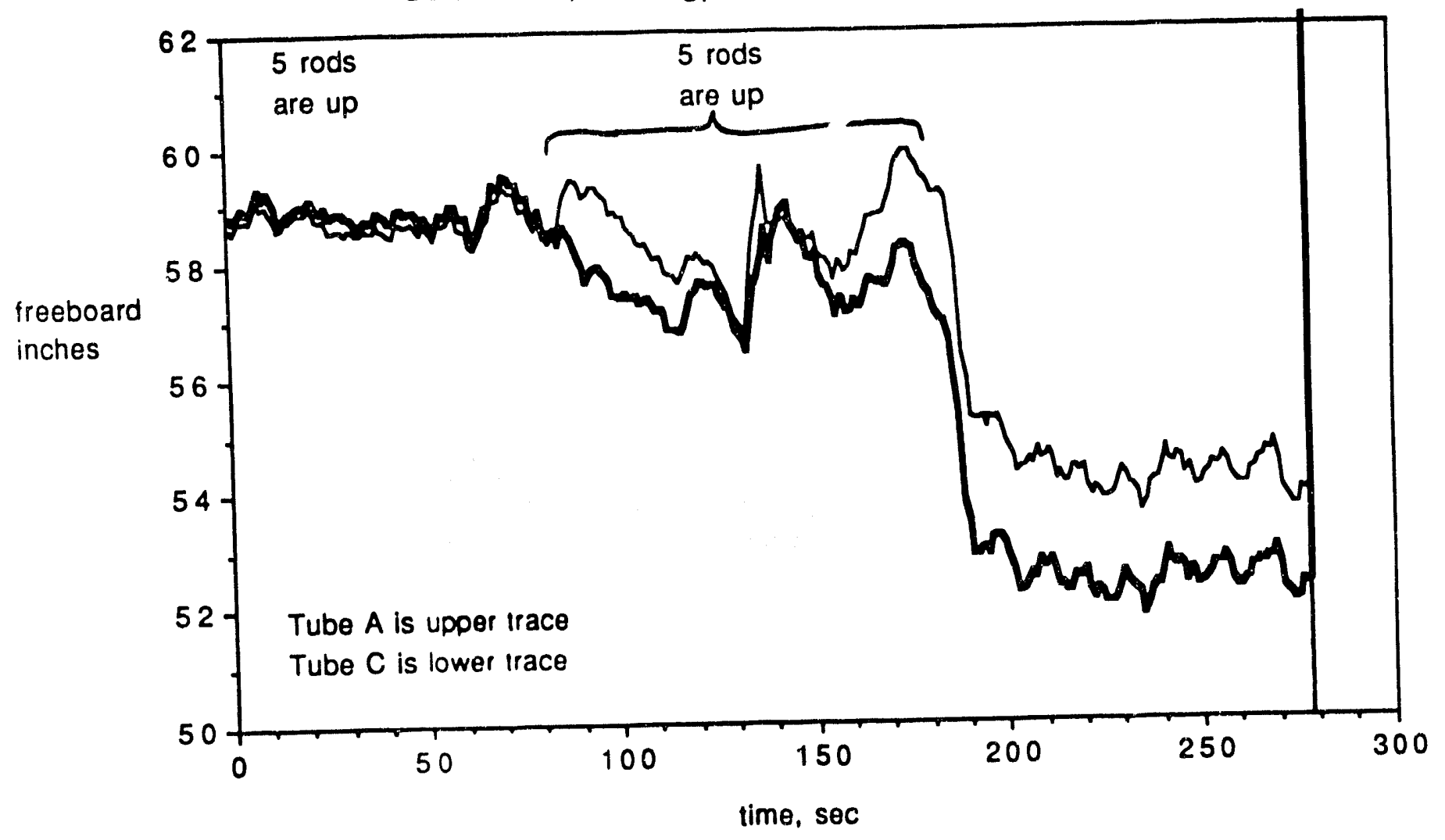

Figure 21

Pin Pressure Transient as Five Control Rods are

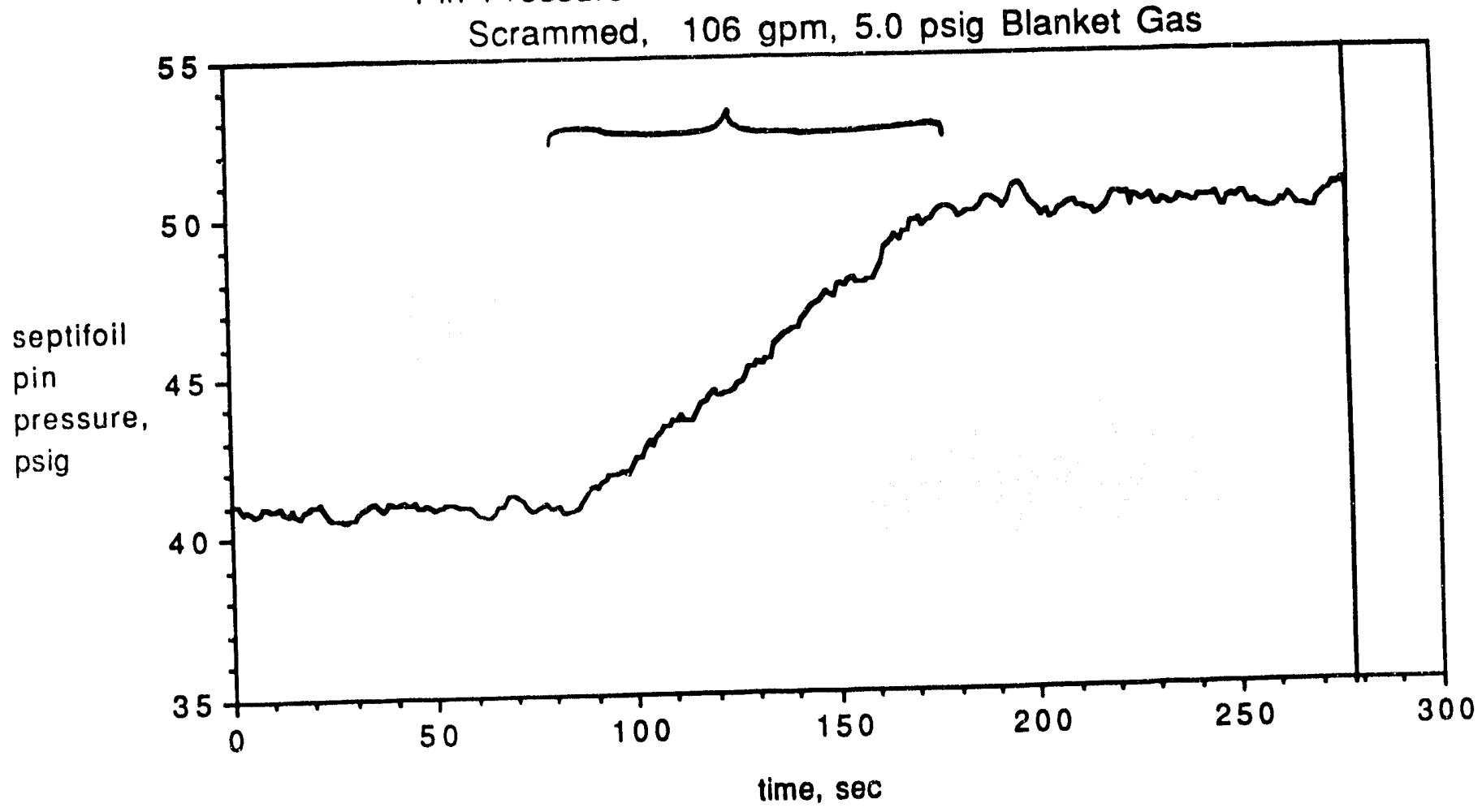




\section{Appendix A \\ Loop Calibration of DAS and Software}

A loop calibration involving three tests was run to simultaneously check the instruments, the DAS, the Workbench worksheet and the Trapeze spreadsheet. For the first test test system overflow was maintained at the normal level, which was measured with a ruler. The overflow pressurizes the flow loop. The flow loop thermometer was placed in a beaker of water at about $30^{\circ} \mathrm{C}$ along with a calibrated thermometer. All instruments were logged. Then the overflow level was raised to another level which was also measured with a ruler, the temperature of the water was changed and the instruments were again logged. Finally, the flow neter was removed from the flow loop and calibrated. However, the flow meter was kept connected the DAS as well as the voltmeter used in the calibration. The resulting Workbench data files were imported to the Trapeze program. The outputs of the Trapeze spreadsheet are attached and are compared below with independently determined values. Also attached is a figure showing the important dimensions. Additional details are recorded in the log book, WSRC-TR-92-273.

Comparision of freeboards measured by ruler and DAS

By ruler

Test $11239.5^{\prime \prime}+84.7^{\prime \prime}+102.9^{\prime \prime}-354.5^{\prime \prime}=72.6 "$

Test $2 \quad 239.5^{\prime \prime}+84.7^{\prime \prime}+102.9^{\prime \prime}-369.8^{\prime \prime}=57.3^{\prime \prime}$

Comparision of pressures measured by ruler and DAS

TR-428

Test 1

Test 2

TR-432

Test 1

Test 2

TR-436

Test 1

Test 2
By ruler

$354.5 " / 12 \quad 62.1 / 144=12.74 \mathrm{psi}$

$369.8 " / 12 \quad 62.1 / 144=13.29 \mathrm{psi}$

$\left(354.5^{\prime \prime}+10.8 "\right) / 12 \quad 62.1 / 144=13.12 \mathrm{psi}$

$(369.8 "+10.8 ") / 12 \quad 62.1 / 144=13.68 \mathrm{psi}$

$13.17 \mathrm{psi}$

$13.66 \mathrm{psi}$

By Trapeze

$12.75 \mathrm{psi}$

$13.26 \mathrm{psi}$

A C

71.5" 71.6"

57.5 " 57.6" 
WSRC-TR-92-370

page 35

Comparison of temperature measured by thermometer (TR-2896) and DAS

$\begin{array}{lll} & \text { thermometer } & \text { DA } \\ \text { Test } 1 & 35.5^{\circ} \mathrm{C} & 35.1^{\circ} \mathrm{C} \\ \text { Test } 2 & 33.7^{\circ} \mathrm{C} & 32.7^{\circ} \mathrm{C}\end{array}$

The difference did not exceed $1^{\circ} \mathrm{C}$ which is acceptable.

Comparison of flow measured by the bucket stopwatch technique and the DAS

The weight of water collected was $2531 \mathrm{lb}$. in 3 minutes 1.45 seconds. The temperature was $22^{\circ} \mathrm{C}$. This flow is $100.5 \mathrm{gpm}$. The Trapeze flow was $99.8 \mathrm{gpm}$ of a difference of $0.7 \mathrm{gpm}$, which is acceptable. 

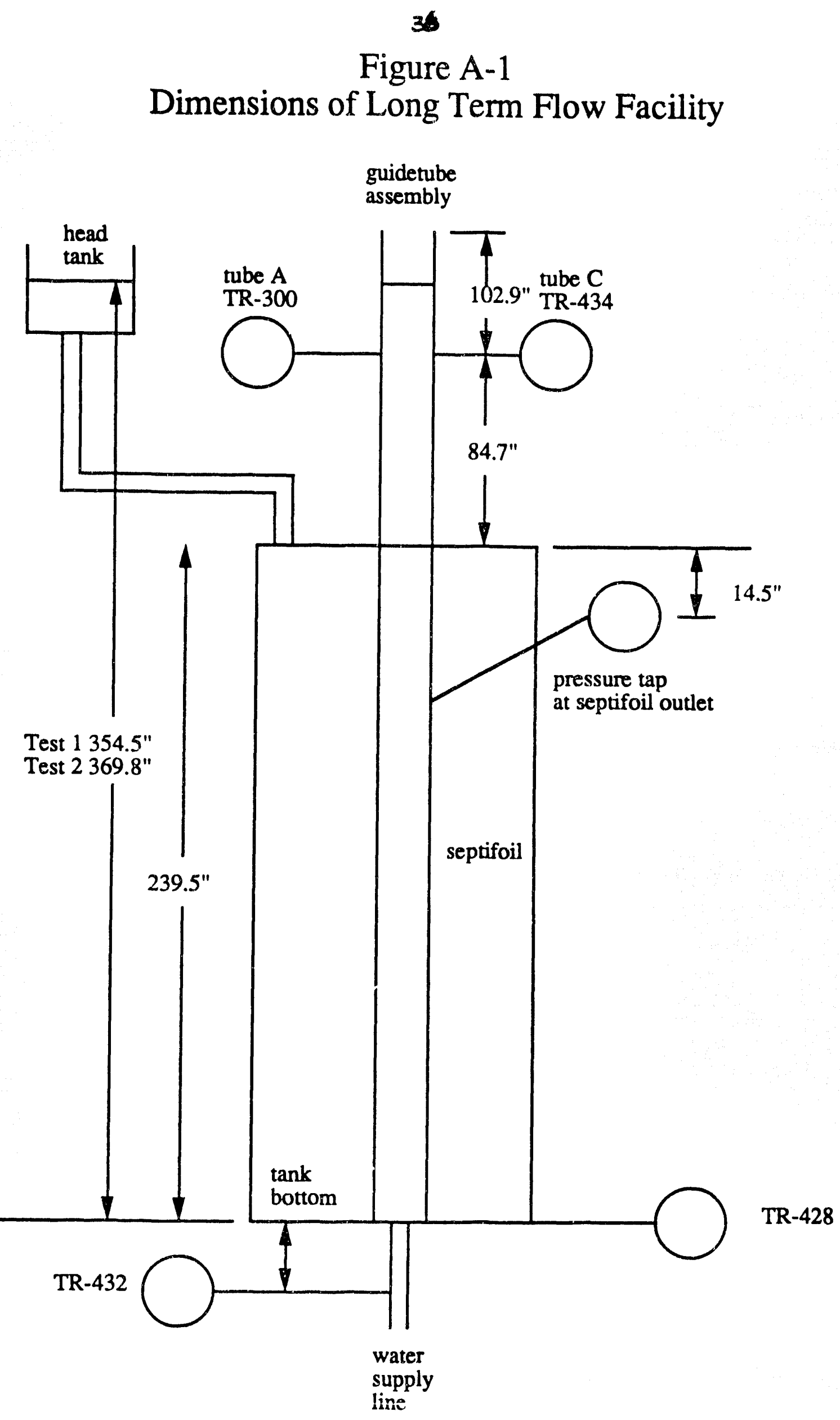


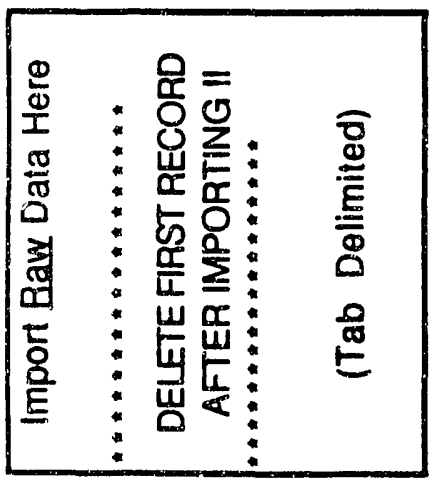

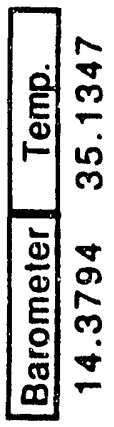

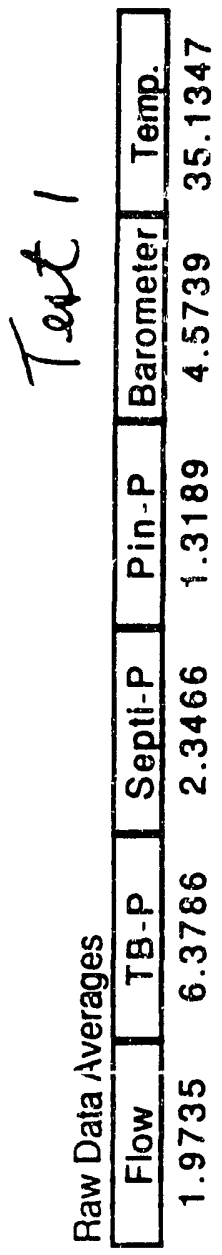

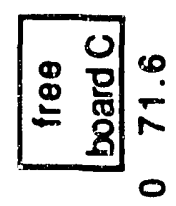

$\frac{\frac{0}{0}}{\frac{0}{5}}$

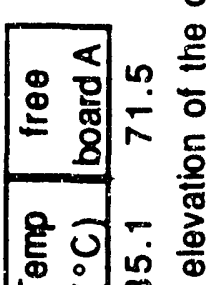
$\stackrel{1}{\overline{1}}$ 의 言 ․ㅛ $\stackrel{0}{\frac{\omega}{2}}$ 둥 a

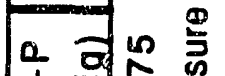
官

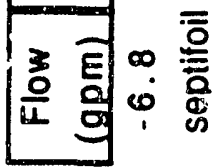

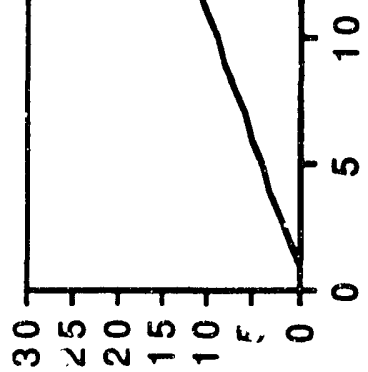
$\begin{array}{llll}0 & 0 & 0 & 0\end{array}$

은

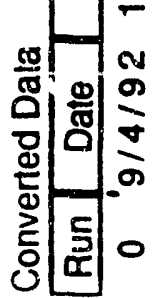

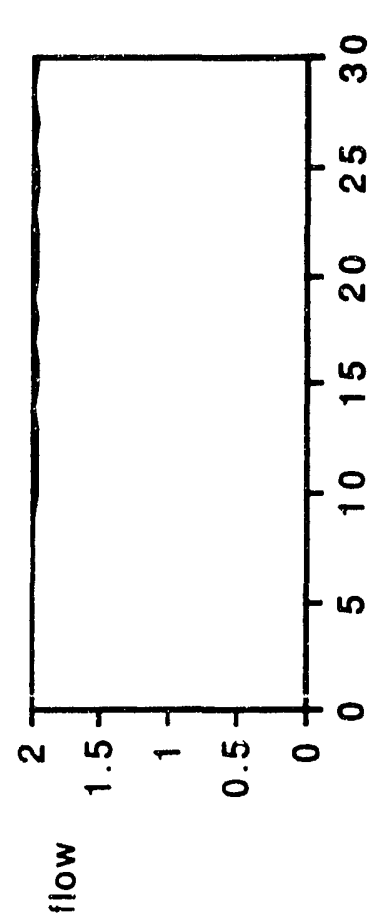

ธิ ำ

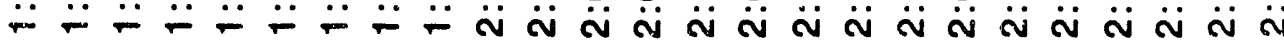

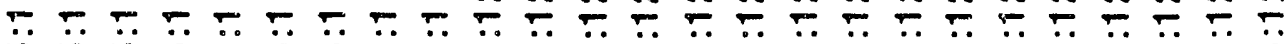

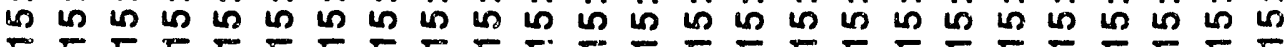

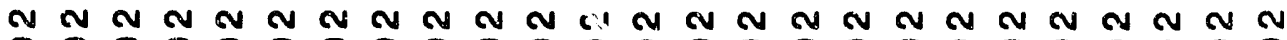

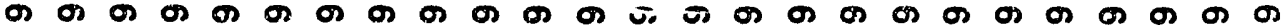

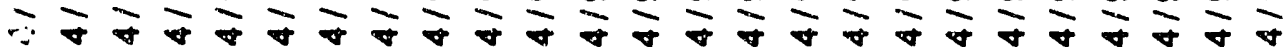

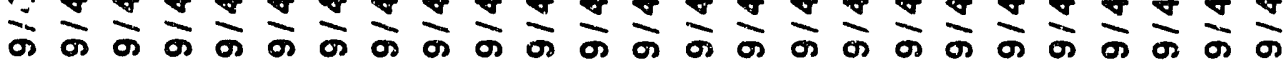

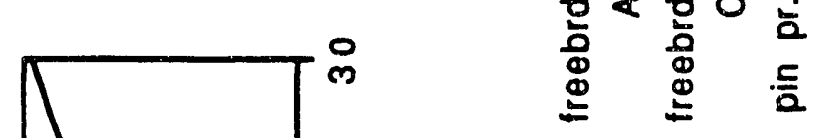

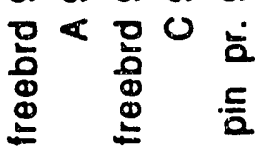

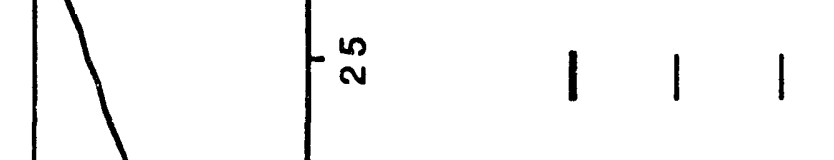

$\begin{array}{cccc}0 & 0 & 0 \\ 0 & 0 & 0 & 0\end{array}$

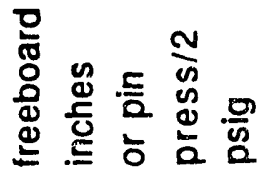


움

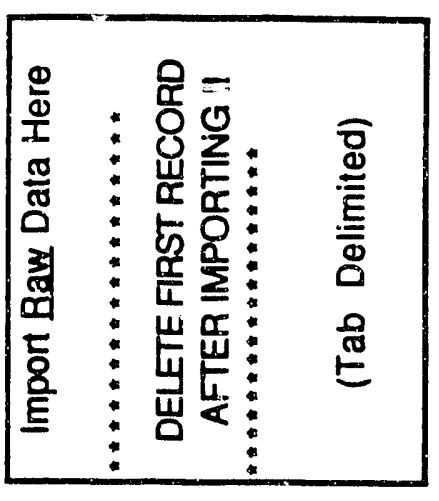

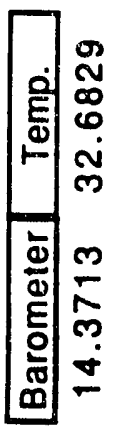

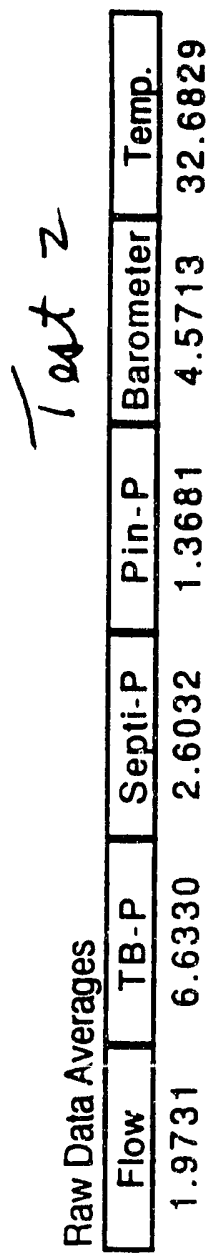

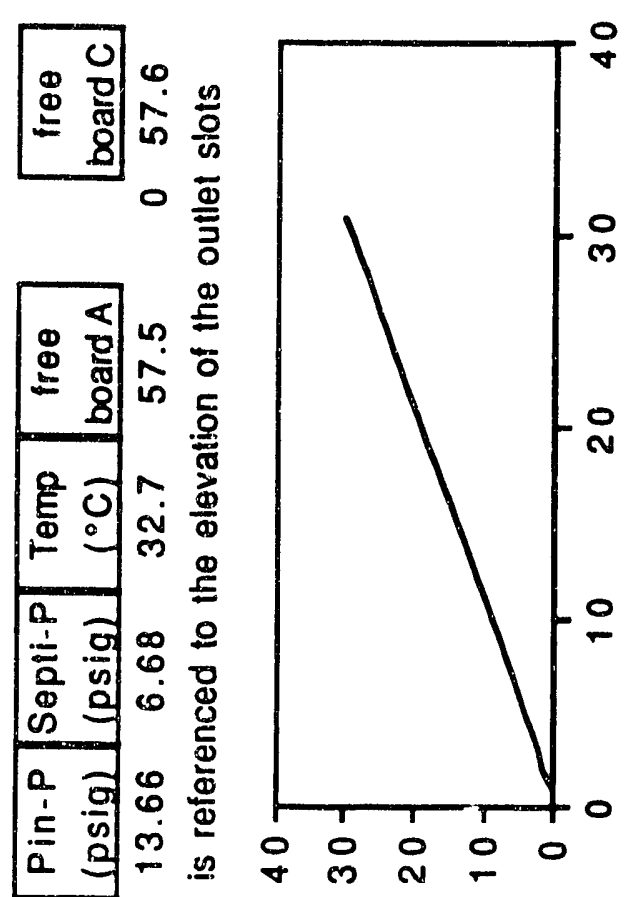

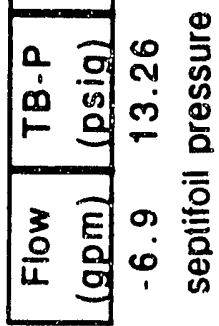
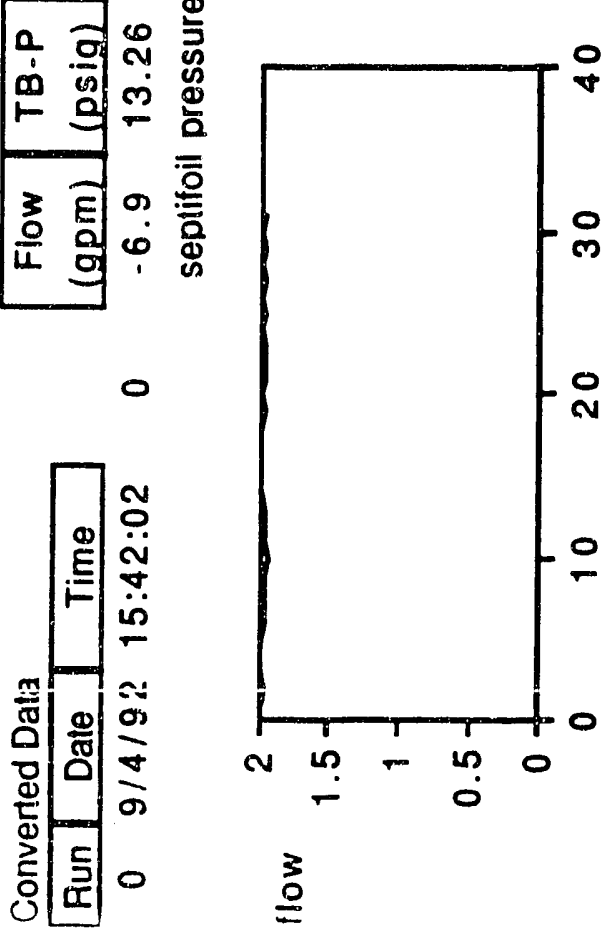

$\stackrel{3}{\underline{3}}$

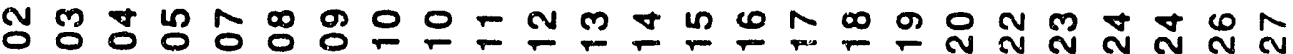

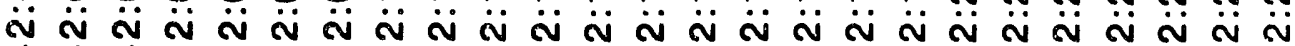

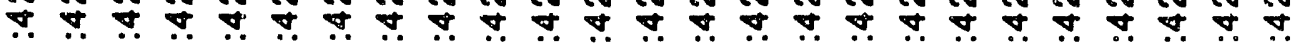

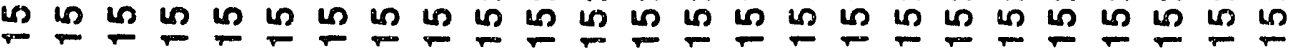

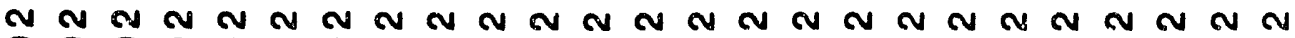

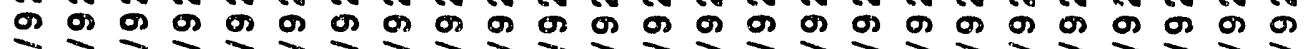

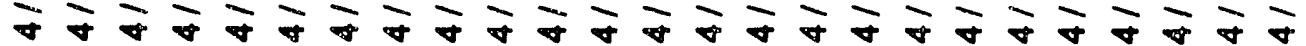

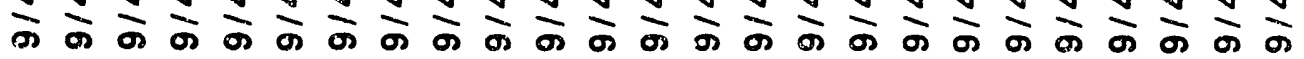

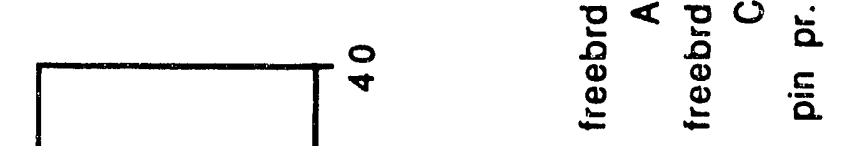

a 2 (

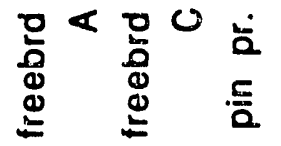

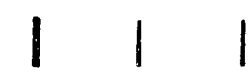

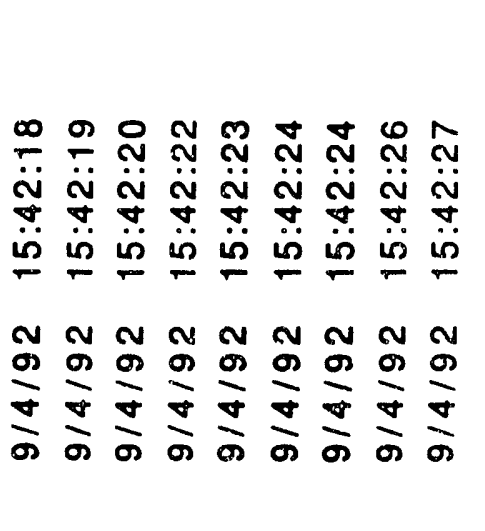


$W S R C-T R-92-370$

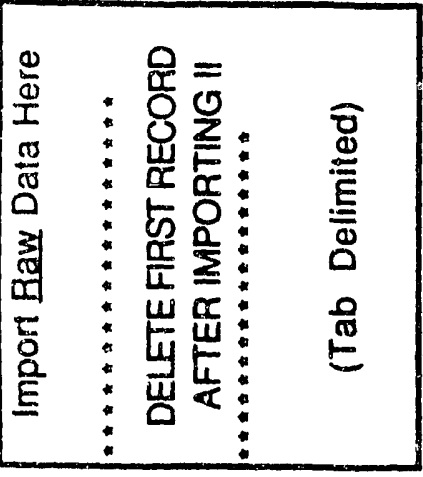

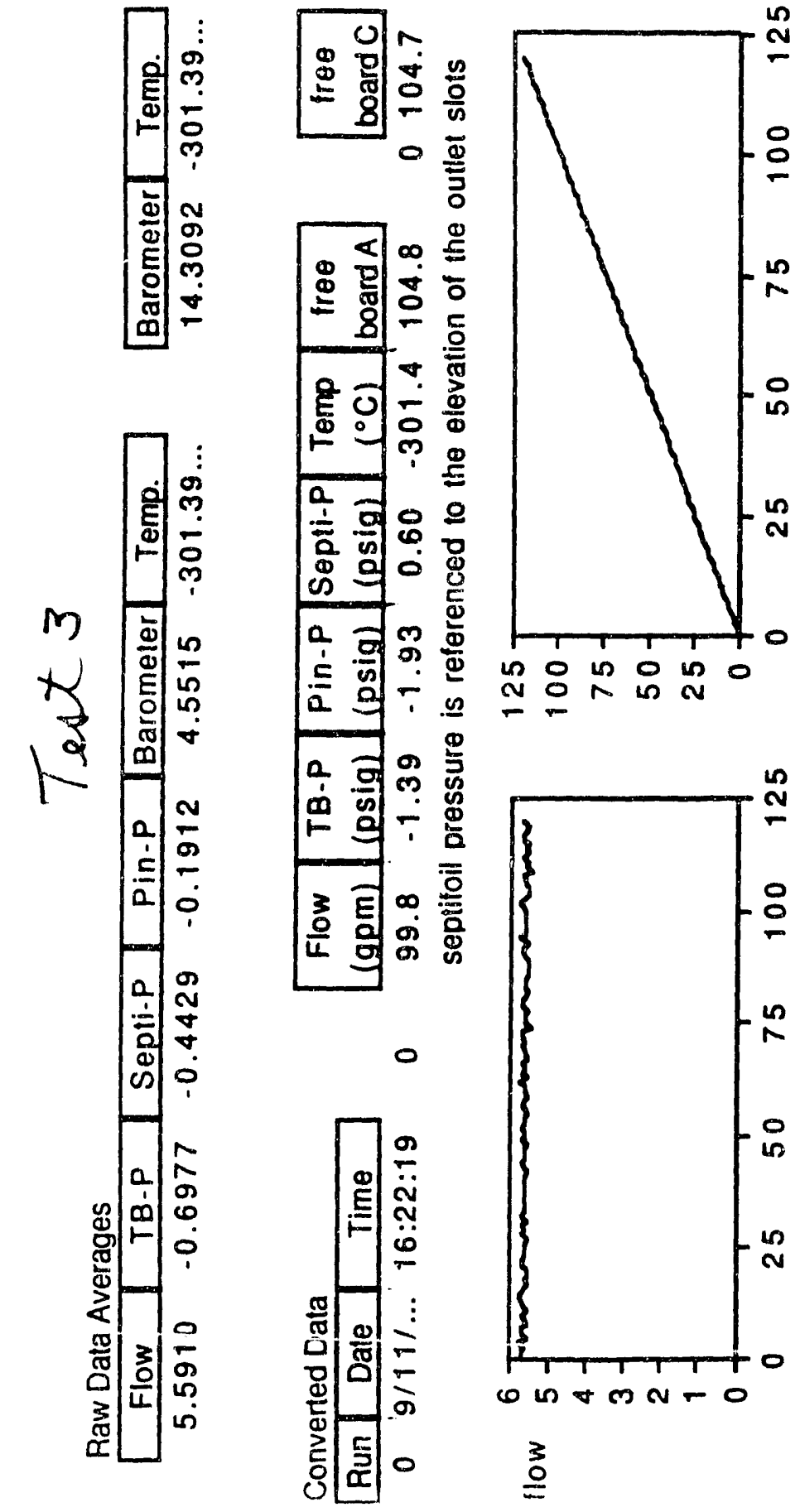
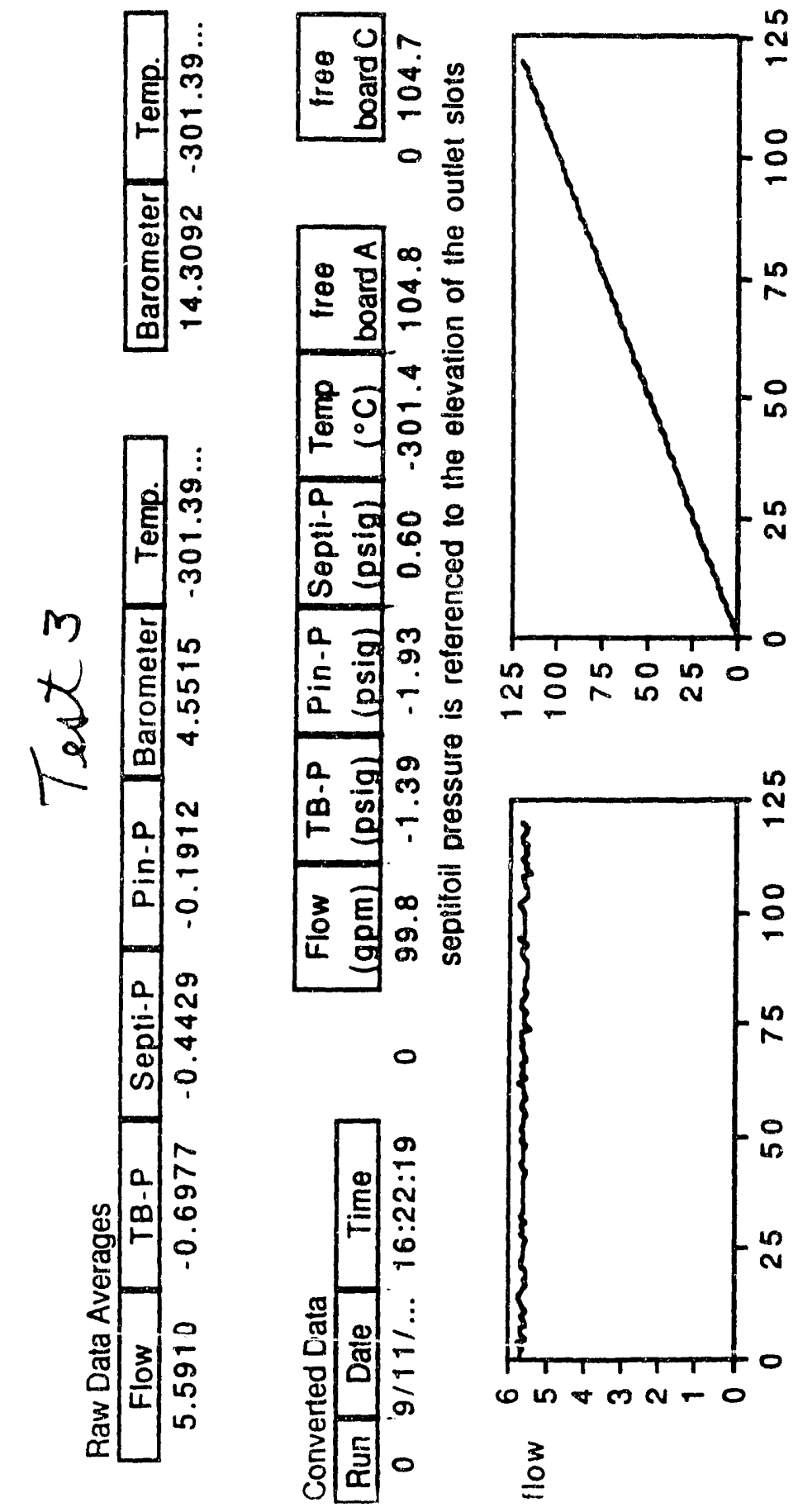

r.

.

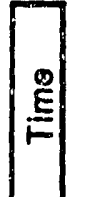

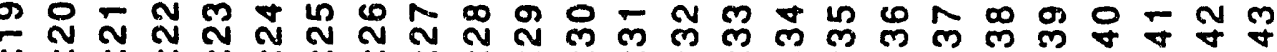
$\ddot{\sim} \ddot{\sim} \ddot{\sim} \ddot{\sim} \ddot{\sim} \ddot{\sim} \ddot{\sim} \ddot{\sim} \ddot{\sim} \ddot{\sim} \ddot{\sim} \ddot{\sim} \ddot{\sim} \ddot{\sim} \ddot{\sim} \ddot{\sim} \ddot{\sim} \ddot{\sim} \ddot{\sim} \ddot{\sim} \ddot{\sim} \ddot{\sim} \ddot{\sim} \ddot{\sim} \ddot{\sim}$ يִ بָ ب়

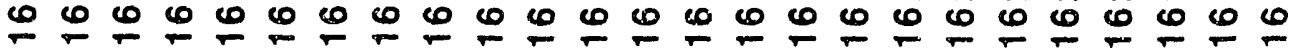

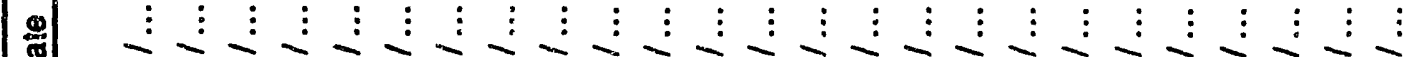

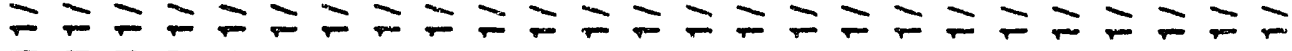

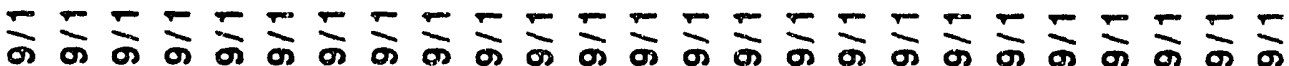

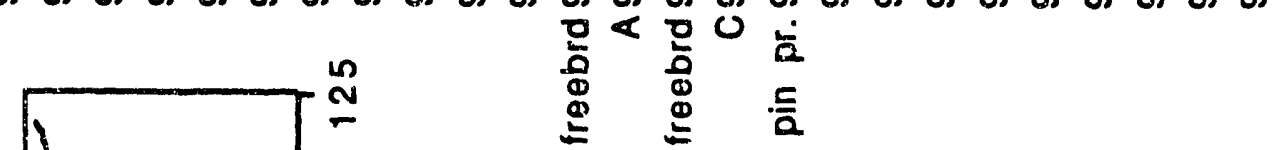

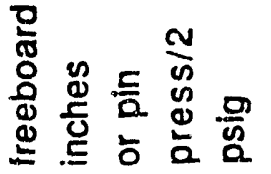




\section{Appendix B Chronology of Early Scoping Experiments}

This chronology is included because small changes were made during the course of the scoping tests and critical tests. The chronology will allow the reader to reconstruct the status of the test rig for any test, scoping or critical. Scoping data is not included in this document but may be included in a later document.

May 26 The Lexan plates that simulate the Poison Plate and the top shield were installed with a 1" spacing. A pressure tap was installed 0.94" above the bottom of the semipermanent sleeve in the LTFF. The seven control rods were installed as a bundle in the septifoil 0.5 inch above the orifice plate. Therefore, their heights could not be controlled separately. The pressure tap indicated the same head as before.

May 27 The perimeter of the plates simulating the Poison Plate and the top shield was closed off to create much more restrictive outlet conditions to simulate pluggage in the region above the Poison Plate. Some tests were run. The pressure tap indicated slightly higher pressures than before, but not enough to explain the leak out the top of the septifoils in K Reactor. The DAS was connected to the instruments. The Sensotec pressure gage (TR-20075) was repositioned outside the uppermost porthole. A log switch was added to the DAS program. A purge line was added to the septifoil pressure line (TR-20075). Transient data was taken starting at 09:00. In the course of experiments the partial rods were pulled out while leaving the full rods in. Water was observed flowing out of the holes at the top of the extensions for the partial rods. Around noon the guide tube assembly was installed to make the apparatus more prototypical. A cylindrical weight called a clamshell was added to the bottom of the guide tube assembly. Pullers were attached and pinned to the partial rods. Other pins were held in place with blank tubes inserted in the guides. Starting at 13:00 runs were made at $100 \mathrm{gpm}$. At about 18:00 a valve was installed on the tank vent. The overflow bucket level was moved to $30^{\prime} 6.5^{\prime \prime}$. The guide tube assembly was removed. At about 2000 TR-301 was installed to read pin pressure. The overflow level was changed to 29'5.75". Tygon sight tubes were added to six outer guide tubes. The four outer full rods were held down. The two partial rods could be lifted with the hoist. The center rod was equipped with different lifting device.

May 28 The guide tube assembly and clamshell were reinstalled. A new Heise gage with a analog voltage output (TR-436) was installed to read pin pressure. Data were taken with the two partial rods at different elevations. Around 03:00 six foot extensions were added to the six guide tube sight tubes. Runs were made with the center control rod extended 14' 3.5". At about 04:30 ropes were attached to the partial rods. The overflow bucket was lowered. More data were taken at $100 \mathrm{gpm}$ and variable partial rod positions. Around 08:00 the tank bottom tap was moved and connected to the monitor pin (P4). The barometer, TR-710, was connected to the DAS. The tank bottom pressure gage was replaced with a Heise gage. The upper guide assembly was removed and center rod extension puller was replaced with a segmented puller to facilitate pulling the center rod in future runs. The simulated Poison Plate and shield plate were removed. The spacing was changed from 1" to 0.75 " and reinstalled. The perimeter blockage was not reinstalled. The guide tube assembly and clamshell were reinstalled. Data was collected. Around 19:30 the line from tank bottom to the overflow bucket was was removed. A line was connected between the bucket and the 2" flange at tank top that was previously used for the tank vent. This decreased the pressure drop and made the pressure control more effective.

May 29 Around 01:00 the $\mathrm{G}$ control rod spacer was changed so that $\mathrm{G}$ rod could be lifted 
above the exit slots in the septifoil and also allow access to the partial rods from the hoist. Data was collected. At 08:00 the upper guide tube assembly was removed to design a method of pulling the full rods separately from the partial rods. At 16:35 the guide tube assembly and clamshell were reinstalled with the B tube facing the keyway per ST-MDX510074. The LTFF pumps were reconnected for closed loop operation. A 1/4" J Type thermocouple was inserted in the inlet water line and connected to the DAS. The overflow bucket discharge was moved to 29' 5.5'. Critical data collection began at 17:00. 


\section{Appendix C Procedure for Startup and Scram Tests}

\section{Test 1}

a. Pull the two partial rods, A and D, up to 35.4" and hold them there.

b. Log 30 seconds and note the freeboards.

c. Attach the hoist to rod number 1 .

d. Start a new $\log$, raise rod 1 at a rate of $16 \mathrm{inch} / \mathrm{min}$ or more.

e. Watch the freeboard in $\mathrm{A}$ or $\mathrm{D}$, whichever is more convenient. Note the minimum freeboard and the approximate rod height it occurs at.

f. When rod 1 reaches the top, 148 inches, stop the log. Keep rod 1 suspended at 148 inches.

g. Repeat steps $\mathrm{c}$ through $\mathrm{f}$ with rod 2. Keep rod 2 suspended at 148 inches.

g. Repeat steps $c$ through $f$ with rod 3 . Keep rod 3 suspended at 148 inches.

h. Gang rods 1,2 and 3 together and connect them to the hoist. You can lower them to do this. Raise them back to 148 inches. At this time the two partial rods are still at 35.4".

i. Start the log.

j. Lower the rods at about $1.6 \mathrm{inch} / \mathrm{sec}$. Watch the freeboard in A or D, whichever is more convenient. Note the ininimum freeboard and the approximate rod height it occurs at.

k. Stop the log.

Test 2

Repeat test 1 except that the partial rods are at 18 ".

\section{Test 3}

a. Keep the partial rods at $18 "$. Rod 5 stays down.

b. In preparation for data collection raise rods 1,2 and 3 to 148 inches and hold them up.

c. Connect the hoist to rod 4.

d. Start a new log, raise rod 4 at a rate of $16 \mathrm{inch} / \mathrm{min}$ or more.

e. Watch the freeboard in $A$ or $D$, whichever is more convenient. Note the minimum freeboard and the approximate rod height it occurs at.

f. When rod 4 reaches the top, 148 inches, stop the log.

g. Lower the four rods, gang them together and connect the hoist to them. Raise them to 148 inches

h. Start the log.

i. Lower the rods at about $1.6 \mathrm{inch} / \mathrm{sec}$. Watch the freeboard in A or D, whichever is more convenient. Note the minimum freeboard and the approximate rod height it occurs at.

j. Stop the log.

Test 4

a. Keep the partial rods at $18 "$.

b. Connect the hoist to rods $1,2,3,4$ and 5 together.

c. Raise them to 148 inches.

d. Start the log.

e. Lower the rods at about $1.6 \mathrm{inch} / \mathrm{sec}$. Watch the freeboard in $\mathrm{A}$ or $\mathrm{D}$, whichever is more convenient. Note the minimum freeboard and the approximate rod height it occurs at.

f. Stop the log. 


\section{Appendix D Results of Startup and Scram Tests}

All tests were run at a flow of 70 gpm and the usual tank bottom pressure, about 12.75 psig.

Tests were run the evening of June 5, 1992.

Test 1

time actions and observations

2027 Partial rods are at 35". Freeboard is 30" with all full rods down

Began raising rod 1. minimum freeboard was 27" at a rod height of 136 " which was maximum elevation.

computer data file: SEPTI Q 2015 06/05/92

2052 began raising rod 2, freeboard is 27 " with rod 2 down

freeboard was $26^{\prime \prime}$ from 3' to $11^{\prime}$.

minimum freeboard was 24 " at a rod height of 136" which was maximum elevation SEPTI Q 2100 06/05/92

2109 began raising rod 3 , freeboard is 24 " with rod 3 down

minimum freeboard was 22 " at a rod height of 136 " which was maximum elevation SEPTI Q 2130 06/05/92

2211 began dropping rods 1,2 and 3 , at start freeboard was $23 "$.

minimum freeboard was 23 ", maximum freeboard was $30^{\prime \prime}$.

SEPTI Q 2200 06/05/92

Test 2

2027 Partial rods are at 18". Freeboard is 25" with all rods down SEPTI Q 2225 06/05/92

2235 Began raising rod 1. minimum freeboard was 23" at a rod height of 122"

SEPTI Q 2230 06/05/92, raise time $3.7 \mathrm{~min}$, final freeboard was 28 "

2256 Began raising rod 2. minimum freeboard was 26" at a rod height of 122"

SEPTI Q 2230 06/05/92, raise time $4.8 \mathrm{~min}$, final freeboard was 28 "

2307 Began raising rod 3. minimum freeboard was 27" at a rod height of 122"

SEPTI Q 2230 06/05/92, raise time $4.8 \mathrm{~min}$, final freeboard was 28 "

2211 began dropping rods 1,2 and 3 , at start freeboard was 28 ".

minimum freeboard was 22 ", maximum freeboard was $26 "$.

SEPTI Q 2325 06/05/92

Test 3

2333 Partial rods are at 18". Rods 1, 2 and 3 are full out. Freeboard is 28" SEPTI Q 2355 06/05/92

2351 Began raising rod 4. minimum freeboard was 26" at a rod height of 122" SEPTI Q 2230 06/05/92, raise time $6.7 \mathrm{~min}$, final freeboard was 26 "

0015 began dropping rods 1, 2, 3 and 4, at stari freeboard was 26".

minimum freeboard was 20 " at rod height of 110 ", final freeboard was 26 ". time to lower was $84 \mathrm{sec}$. SEPTI Q 0010 06/06/92 
Test 4

0020 Partial rods are at 18". Rods 1, 2, 3, 4 and 5 are full out. Freeboard is 24"

0022 began dropping rods $1,2,3,4$ and 5, start freeboard was 24".

minimum freeboard was 16 " at rod height of 113 ", final freeboard was $25 "$. time to lower was $79 \mathrm{sec}$. SEPTI Q 0025 06/06/92 

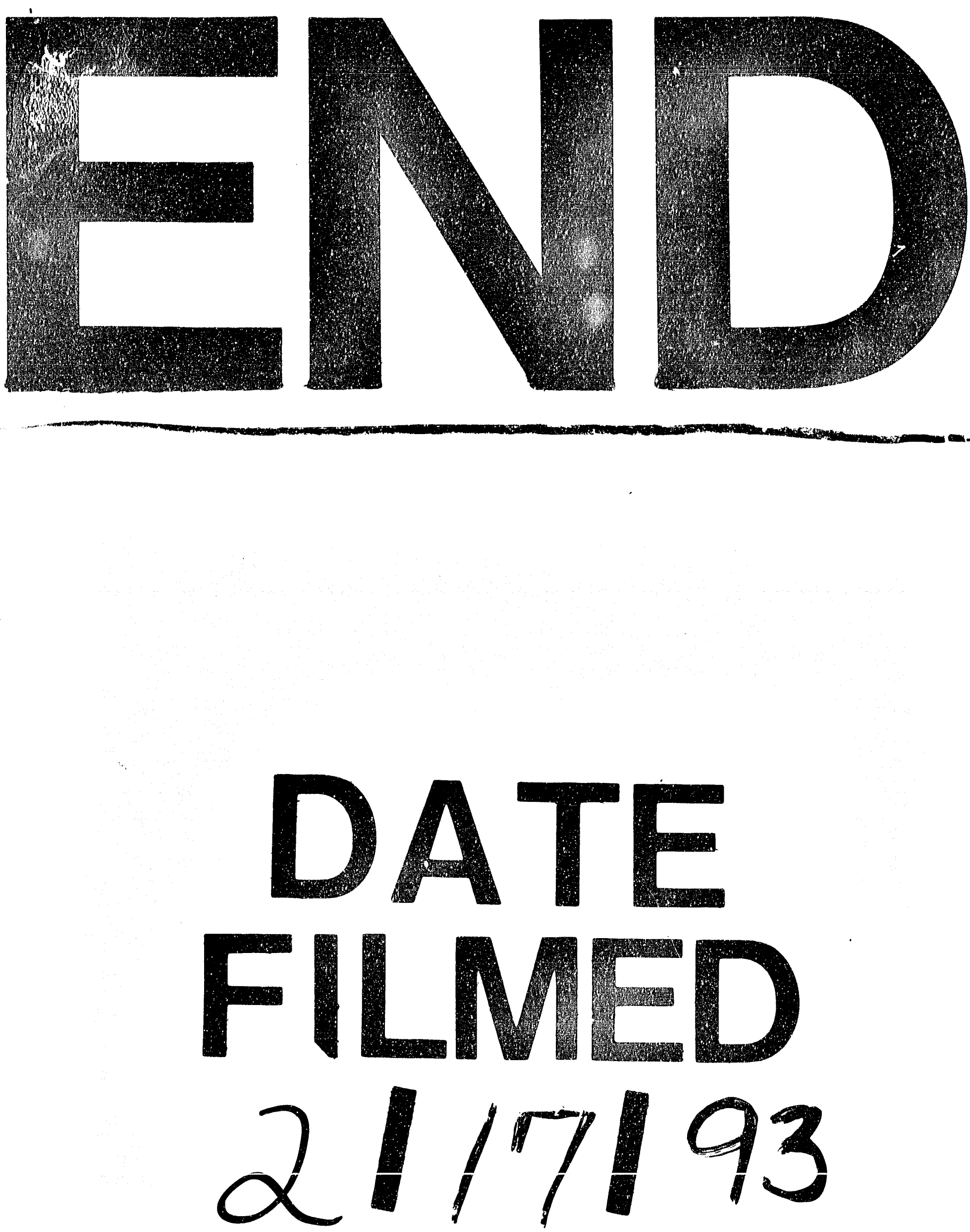
